\title{
Effects of silver nanoparticles and ions on a co-culture model for the gastrointestinal epithelium
}

Anastasia Georgantzopoulou ${ }^{1,8}$, Tommaso Serchi ${ }^{1}$, Sébastien Cambier ${ }^{1}$, Céline C. Leclercq ${ }^{1}$, Jenny Renaut ${ }^{1}$, Jia Shao ${ }^{1,2}$, Marcin Kruszewski ${ }^{3,4}$, Esther Lentzen ${ }^{5}$, Patrick Grysan ${ }^{5}$, Santhana Eswara ${ }^{5}$, Jean-Nicolas Audinot ${ }^{5}$, Servane Contal', Johanna Ziebel ${ }^{1}$, Cédric Guignard ${ }^{1}$, Lucien Hoffmann ${ }^{1}$, AlberTinka J. Murk ${ }^{6,7}$ and Arno C. Gutleb ${ }^{1 *}$

\begin{abstract}
Background: The increased incorporation of silver nanoparticles (Ag NPs) into consumer products makes the characterization of potential risk for humans and other organisms essential. The oral route is an important uptake route for NPs, therefore the study of the gastrointestinal tract in respect to NP uptake and toxicity is very timely. The aim of the present study was to evaluate the effects of Ag NPs and ions on a Caco-2/TC7:HT29-MTX intestinal co-culture model with mucus secretion, which constitutes an important protective barrier to exogenous agents in vivo and may strongly influence particle uptake.
\end{abstract}

Methods: The presence of the mucus layer was confirmed with staining techniques (alcian blue and toluidine blue). Mono and co-cultures of Caco-2/TC7 and HT29-MTX cells were exposed to Ag NPs (Ag 20 and $200 \mathrm{~nm}$ ) and AgNO 3 and viability (alamar blue), ROS induction (DCFH-DA assay) and IL-8 release (ELISA) were measured. The particle agglomeration in the media was evaluated with DLS and the ion release with ultrafiltration and ICP-MS. The effects of the $\mathrm{Ag} \mathrm{NPs}$ and $\mathrm{AgNO}_{3}$ on cells in co-culture were studied at a proteome level with two-dimensional difference in gel electrophoresis (2D-DIGE) followed by Matrix Assisted Laser Desorption lonization - Time Of Flight/ Time Of Flight (MALDI-TOF/TOF) mass spectrometry (MS). Intracellular localization was assessed with NanoSIMS and TEM.

Results: The presence of mucus layer led to protection against ROS and decrease in IL-8 release. Both Ag 20 and $200 \mathrm{~nm}$ NPs were taken up by the cells and Ag NPs 20 nm were mainly localized in organelles with high sulfur content. A dose- and size-dependent increase in IL-8 release was observed with a lack of cytotoxicity and oxidative stress. Sixty one differentially abundant proteins were identified involved in cytoskeleton arrangement and cell cycle, oxidative stress, apoptosis, metabolism/detoxification and stress.

Conclusions: The presence of mucus layer had an impact on modulating the induced toxicity of NPs. NP-specific effects were observed for uptake, pro-inflammatory response and changes at the proteome level. The low level of overlap between differentially abundant proteins observed in both $\mathrm{Ag} \mathrm{NPs}$ and $\mathrm{AgNO}_{3}$ treated co-culture suggests size-dependent responses that cannot only be attributed to soluble Ag.

Keywords: Intestinal co-culture, Mucus layer, Proteomics, Toxicology, Silver nanoparticles

\footnotetext{
* Correspondence: arno.gutleb@list.lu

${ }^{1}$ Environmental Research and Innovation (ERIN) Department, Luxembourg Institute of Science and Technology (LIST), 5 avenue des Hauts-Forneaux, L-4362 Esch-sur-Alzette, Luxembourg

Full list of author information is available at the end of the article
} 


\section{Background}

Nanotechnology has brought about many advances in various fields from medicine and consumer products to environmental remediation. Nanotechnology has also raised many environmental and human health concerns due to the continuous increase in use and application of nanoparticles (NPs, all three dimensions in the order of $100 \mathrm{~nm}$ or less). Silver nanoparticles (Ag NPs) are commonly used in consumer products and numerous studies have shown size dependent effects, that differ from ionic $\mathrm{Ag}$, in both animal models as well as in vitro cell culture models [1]. Among the reported effects are increased reactive oxygen species (ROS) levels, DNA damage and cell cycle arrest [2].

There is still a lack of knowledge about the fate and effects of Ag NPs on the gastrointestinal tract after oral exposure. This uptake route is possible via accidental ingestion during the production or due to their presence in water and in the food chain (due to their increased use in food preservation, food packaging material and water disinfection), therefore the gastrointestinal tract could be a target organ for Ag NP exposure [3, 4]. However, there are only a few studies dealing with adverse effects of NPs on the gastrointestinal epithelium [5-12]. The use of co-cultures and organo-typic culture systems has become more and more popular in toxicology over the last years due to the increased demand for more meaningful in vitro tests that can better mimic the in vivo situation, especially for the toxicity assessment of the increasing range of NPs [13]. In many different studies, co-culture systems have been proven to react in a more realistic way and to be more predictive of the in vivo response $[6,14,15]$. Caco- 2 cells are widely used as a model for the intestinal epithelium in studies for drug permeability or nutrients and xenobiotics absorption and transport [16]. Caco-2 cells were also used in several studies to evaluate the effects of engineered NPs including Ag NPs $[5,7,8,10,11]$. However, the intestinal epithelium, apart from absorptive cells, also contains mucus-secreting cells (goblet cells) among others [17]. The mucus is a selective and dynamic barrier protecting against toxic agents, particulate matter and pathogens [18-20], while facilitating the exchange of nutrients, metabolites, water and gases. Mucus is continuously secreted, therefore particles etc. will have to move upstream to reach the epithelial cells [21]. Mucus is composed of a complex mixture of mucin molecules, lipids, proteins and other components that affect drug transport [20, 22]. It has been suggested that the mucus layer has effects on Fe bioavailability and absorption [23] and it represents an additional barrier to the transport of ions [19]. The mucus layer can trap NPs dependent on the NP size and surface charge [4]. The absence of the mucus layer, though, can potentially lead to over/ under estimation of effects making the need for use of more physiologically relevant models evident.

The aim of the present study was to study the effects of different-sized Ag particles (Ag 20 and $200 \mathrm{~nm}$ ) as well as $\mathrm{AgNO}_{3}$ as a source of ionic silver on an intestinal co-culture model which incorporates mucus for a more realistic simulation of the intestinal epithelium in vitro. The hypothesis is that the mucus layer provides a protective barrier against NPs and ions, and that mucinNPs complexes modify the reactive surface and lead to a different uptake pattern of the NPs depending on particle size. The human colon cancer cells Caco-2/TC7 [24] as well as the human adenocarcinoma mucussecreting cells HT29-MTX [25] were used in the presented intestinal model. These two cell lines represent the two major cell types (absorptive and mucus secreting cells) that are present in the intestinal epithelium in vivo. This model has been described before for iron bioavailability prediction studies [26] and drug absorption [27] including the evaluation of the efficiency of nanocarriers [28]. The metabolic activity of the cells was studied as a measure of cytotoxicity, reactive oxygen species generation and pro-inflammatory effects were studied on Caco-2/TC7, HT29-MTX cells alone and their co-culture. The effect of the Ag NPs and $\mathrm{AgNO}_{3}$ on cells in co-culture was studied at a proteome level by applying two-dimensional difference in gel electrophoresis (2D-DIGE) followed by Matrix Assisted Laser Desorption Ionization - Time Of Flight/ Time Of Flight (MALDI-TOF/TOF) mass spectrometry (MS) technique. This proteomic research can reveal key proteins and pathways that could be altered upon exposure to Ag $\mathrm{NPs}$ and $\mathrm{AgNO}_{3}$ and elucidate whether the observed changes can be related to the different sizes or ion release. In addition, NanoSIMS and TEM analyses were carried out to study potential NP uptake and intracellular localization in relation to particle size.

\section{Results}

\section{Ag particle characterization in cell culture medium}

After suspension of the particles in full cell culture medium, containing $10 \%$ FBS, both Ag 20 and $200 \mathrm{~nm}$ agglomerated and resulted in a broad size distribution with higher hydrodynamic sizes (Fig. 1, Table 1). The $\zeta$ potential for both particles in the FBS-containing cell culture medium was around $-13 \mathrm{mV}$.

The soluble silver present in medium with FBS after 6 and $24 \mathrm{~h}$ of exposure to Ag NPs 20 and $200 \mathrm{~nm}$ was found to be less than $10 \mu \mathrm{g} / \mathrm{L}$, which corresponds to less than $0.01 \%$ release (Table 1 ).

\section{Alamar blue assay}

The viability of the cells in 90:10 co-culture (determined as metabolic activity) significantly decreased at concentrations 


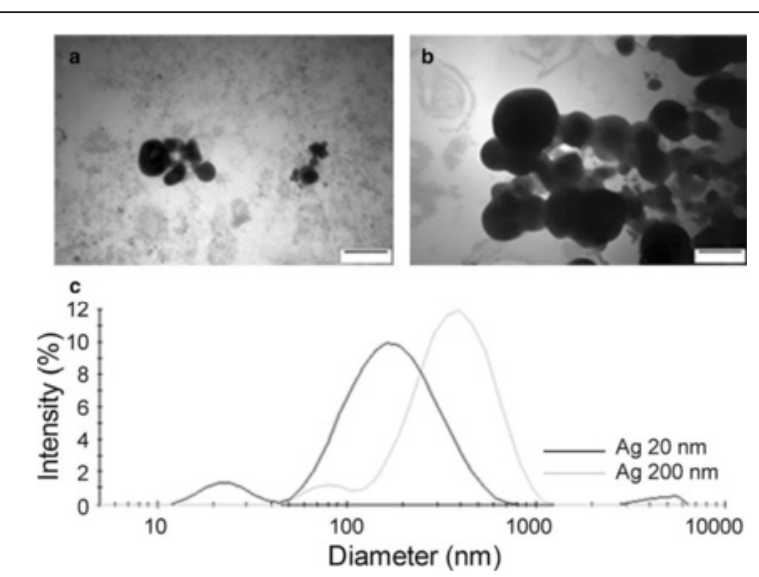

Fig. 1 Particle characterization. Transmission electron microscopy (TEM) images of (a) Ag $20 \mathrm{~nm}$ and (b) Ag $200 \mathrm{mn}$. (c) Size distribution of the particles $\mathrm{Ag} 20 \mathrm{~nm}$ and $\mathrm{Ag} 200 \mathrm{~nm}$ in the cell culture medium with $10 \% \mathrm{FBS}$ at the highest exposure concentration used (100 mg/L). scale bar is $100 \mathrm{~nm}$

higher than $20 \mathrm{mg} / \mathrm{L}$ of $\mathrm{AgNO}_{3}$ after $24 \mathrm{~h}$ of exposure (Fig. 2a). The co-culture was less affected by the treatment with $\mathrm{AgNO}_{3}$ compared to Caco-2/TC7 cells, however the differences were not statistically significant and therefore, only the results obtained with the cells in co-culture are shown. Neither Ag 20 nm nor Ag 200 nm induced cytotoxicity at any of the tested concentrations (0-100 mg/L) (Fig. 2b). Also no cytotoxicity was induced by the Ag particles in the Caco-2/TC7 and HT29-MTX cell lines cultured alone (data not shown).

\section{Intracellular reactive oxygen species formation}

Figure 3 a shows a dose-dependent enhanced production of ROS in both cell lines as well as in the co-culture, upon exposure to the positive control $\mathrm{H}_{2} \mathrm{O}_{2}$ (0.03$3 \mathrm{mM})$. The highest levels of ROS were observed with the HT29-MTX cells upon exposure to the positive control. The response in the co-culture was lower than in Caco-2/TC7 and HT29-MTX alone and the lowest observed effect concentration was $0.03 \mathrm{mM}$ for HT29MTX and $0.1 \mathrm{mM}$ for the Caco-2/TC7 cells alone as well as the co-culture. The Ag NPs and $\mathrm{AgNO}_{3}$ led to ROS production only in the Caco-2/TC7 and HT29-MTX mono-cultures with ROS levels of less than $15 \%$ of the maximal levels induced by the positive control $\mathrm{H}_{2} \mathrm{O}_{2}$. In a cell free system the $\mathrm{Ag}$ particles did not lead to an increased fluorescence signal which was at the same levels as DCFH-DA in the medium alone (Additional file 1: Figure S5).

\section{IL-8 release}

The pro-inflammatory effects of $\mathrm{Ag} \mathrm{NPs}$ and $\mathrm{AgNO}_{3}$ were measured as secretion of interleukine-8 (IL-8) in the supernatant of exposed cells. A dose-dependent effect for $\mathrm{AgNO}_{3}$ in both Caco-2/TC7 as well as in the co-culture after $24 \mathrm{~h}$ of exposure was observed (Fig. 4a). The amount of IL- 8 measured in the supernatant of exposed cells in co-culture was 2 times lower compared to the Caco-2/TC7 cells cultured alone at a concentration of $6.7 \mathrm{mg} / \mathrm{L}$ (highest $\mathrm{AgNO}_{3}$ concentration where no cytotoxic effects were observed). The HT29-MTX cells alone did not respond to stimulation by $\mathrm{AgNO}_{3}$. Increased levels of IL-8 were observed in the Caco-2/TC7 cells and in the co-culture upon exposure to Ag $20 \mathrm{~nm}$ NPs at concentrations above $30 \mathrm{mg} / \mathrm{L}$. On the contrary, treatment with Ag $200 \mathrm{~nm}$ did not induce any statistically significant change. This shows a clear size-dependent effect (6- and 3.5-fold increase in IL-8 release compared to Ag 200 nm-exposed Caco-2/TC7 and cells in co-culture, respectively) (Fig. 4b).

\section{Nanoparticle uptake in the co-culture-NanoSIMS}

In Fig. 5, the elemental distribution of ${ }^{31} \mathrm{P},{ }^{34} \mathrm{~S}$ and ${ }^{107} \mathrm{Ag}$ in cells in co-culture is shown. The elemental distribution of ${ }^{31} \mathrm{P},{ }^{34} \mathrm{~S}$ was chosen in order to localize structures with high $\mathrm{S}$ and $\mathrm{P}$ content (nucleus, proteins etc.) as well as due to the high affinity of $\mathrm{Ag}$ for $\mathrm{P}$ and $\mathrm{S}$. Intracellular presence of Ag was observed for both Ag 20 and $200 \mathrm{~nm}$ as well as $\mathrm{AgNO}_{3}$. After $24 \mathrm{~h}$ of exposure to $100 \mathrm{mg} / \mathrm{L}$ of particles, Ag from the Ag $20 \mathrm{~nm}$ NPs exposure (Fig. 5b) was found to be present in specific areas having a high content of sulfur or phosphorus. A high signal of Ag was also detected in the $\mathrm{AgNO}_{3}$-exposed cells.

\section{Proteomic analysis 2D-DIGE}

At a non-cytotoxic concentration $(1 \mathrm{mg} / \mathrm{L})$ changes in relative abundance were found for 61 proteins upon

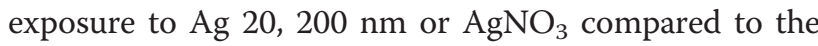
untreated control in the co-culture model. In the $\mathrm{AgNO}_{3}, \mathrm{Ag} 20 \mathrm{~nm}$ and $\mathrm{Ag} 200 \mathrm{~nm}$ - treated cells in coculture, 16, 50 and 6 proteins were altered, respectively (Table 2).

Table 1 Overview of particle characteristics. Main characteristics of the Ag particles studied and the ions released in cell culture medium containing $10 \% \mathrm{FBS}$ after $24 \mathrm{~h}$ at the highest concentration at which the cells were exposed to $(100 \mathrm{mg} / \mathrm{L})$

\begin{tabular}{lllcl}
\hline Particles & Primary size $(\mathrm{nm})$ & Hydrodynamic diameter $(\mathrm{nm})$ & Z potential $(\mathrm{mV})$ & Soluble Ag released $(\mu \mathrm{g} / \mathrm{L})$ \\
\hline Ag $20 \mathrm{~nm}$ & 20 & 129 & -12.8 & $<10(0.01 \%)$ \\
Ag $200 \mathrm{~nm}$ & 200 & 308 & -13.9 & $<10(0.01 \%)$ \\
\hline
\end{tabular}

The $\mathrm{Z}$ potential in MilliQ water was -14.2 and -11 for $\mathrm{Ag} 20$ and $200 \mathrm{~nm}$, respectively while the values in DMEM without phenol red and FBS were +3.5 (Ag $20 \mathrm{~nm}$ ) and $+0.5 \mathrm{mV}(\mathrm{Ag} 200 \mathrm{~nm})$ 


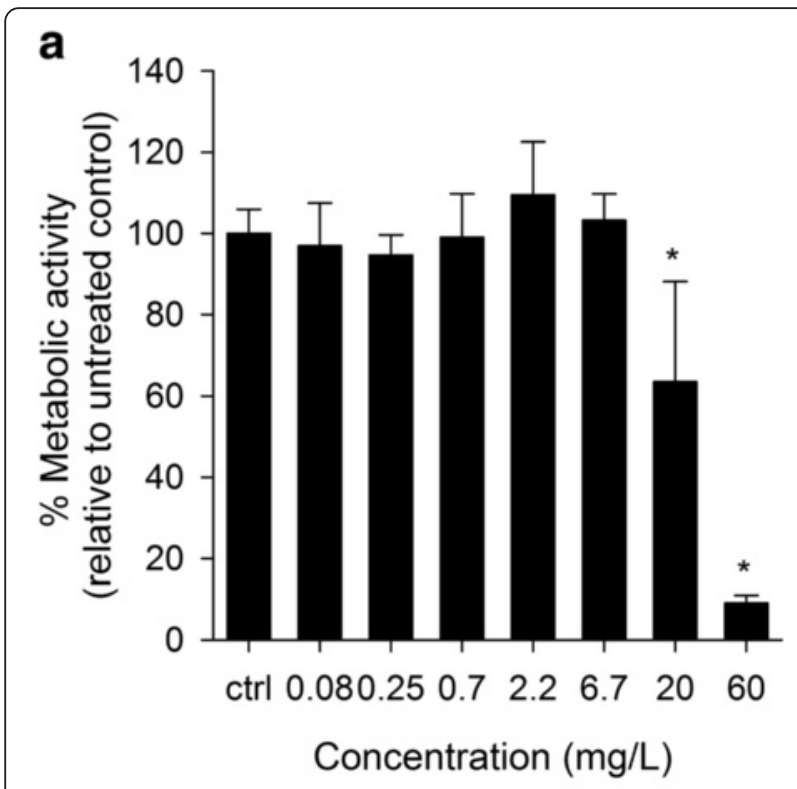

b

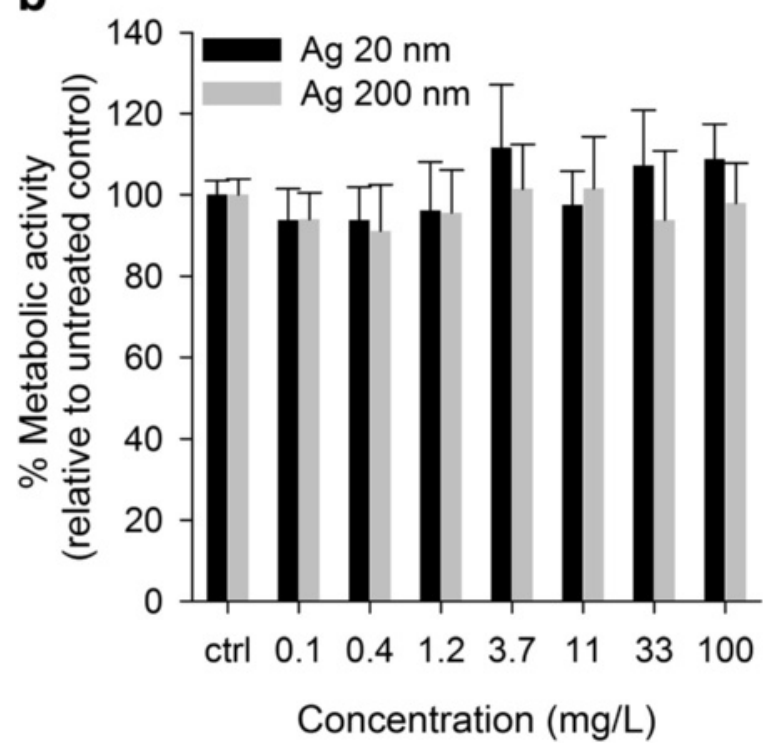

Fig. 2 Effects on metabolic activity. Effects of (a) $\mathrm{AgNO}_{3}$ and (b) $\mathrm{Ag}$ 20 and $200 \mathrm{~nm}$ on the viability (determined as metabolic activity) of Caco-2/TC7 and HT29-MTX cells in co-culture at a 90:10 ratio. After

14 days in culture the cells were exposed for $24 \mathrm{~h}$. Error bars represent the mean \pm SD of 3 independent experiments performed in triplicate. * indicates significant differences of the treatments from the respective untreated controls $(P<0.05)$

The 61 differentially expressed proteins were used to cluster the samples by principal component analysis (PCA) compared to the negative control (Fig. 6). Cocultures treated with $\mathrm{Ag} 200 \mathrm{~nm}$ clustered very close to the negative control, while the $\mathrm{Ag} 20 \mathrm{~nm}$ and $\mathrm{AgNO}_{3}$ treatments showed bigger differences in the proteome compared to the untreated cells or the Ag $200 \mathrm{~nm}$ treated cells. The Ag $20 \mathrm{~nm}$ and $\mathrm{AgNO}_{3}$-induced proteome changes clustered far away from each other. The hierarchical clustering, based on these proteins provided the same overall picture (Additional file 1: Figure S7).

Proteins with significant changes were classified in 6 main categories according to their function (Table 2) involving: cytoskeleton organization and cell cycle regulation, redox regulation, apoptosis, stress response, detoxification/metabolism regulation or in "other functions" when the previous categories did not fit.

The only one protein that was found to be changed by Ag 20 and $200 \mathrm{~nm}$ as well as $\mathrm{AgNO}_{3}$ exposure was peroxiredoxin- 6 that is involved in redox regulation of the cell.

Figure 7 is a representative image showing the picking location for proteins which were altered upon exposure to $\mathrm{Ag} 20 \mathrm{~nm}, \mathrm{Ag} 200 \mathrm{~nm}$ or $\mathrm{AgNO}_{3}$. The fold change and additional information of all differentially abundant proteins in the different treatment groups can be found in Table 2. Detailed information on protein identification is presented in the additional files (Additional file 1: Table S1).

\section{Discussion}

Ag NPs with their increased use in consumer products are likely to reach the environment and humans through either direct or indirect exposure. Although an important uptake route for humans is via ingestion, the effects of NPs and their fate in the gastrointestinal tract are largely unknown. This study describes the evaluation of the uptake, intracellular localization and effects of $\mathrm{Ag}$ NPs and $\mathrm{AgNO}_{3}$ on a gastrointestinal co-culture model simulating the epithelium incorporating a mucus layer. The aim of this study was to incorporate the mucus in order to obtain a more realistic in vitro estimation of the toxic potential of silver particles, as mucus can act as a barrier that impedes, or at least reduces, the interaction between the cells and the NPs that can be dependent on particle size.

In the gastrointestinal epithelium the mucus layer provides a protective barrier against pathogens, digestive enzymes and damage [26]. The staining performed showed that the mucus layer was formed after 14 days in culture and covered the surface of the cell monolayer at the lowest ratio of HT29-MTX cells present (90:10) (Additional file 1: Figures S1-S3). The concentration of goblet cells in the small intestine and under healthy conditions is approximately $10 \%$ [17] and for that reason this ratio was chosen for the study. Low amounts of mucus can be produced by Caco- 2 cells under normal conditions, however this was not observed in our study with the staining techniques used [29].

The NanoSIMS analysis revealed a cellular uptake of $\mathrm{Ag}$ by the cells in co-culture exposed to both 20 and 
a

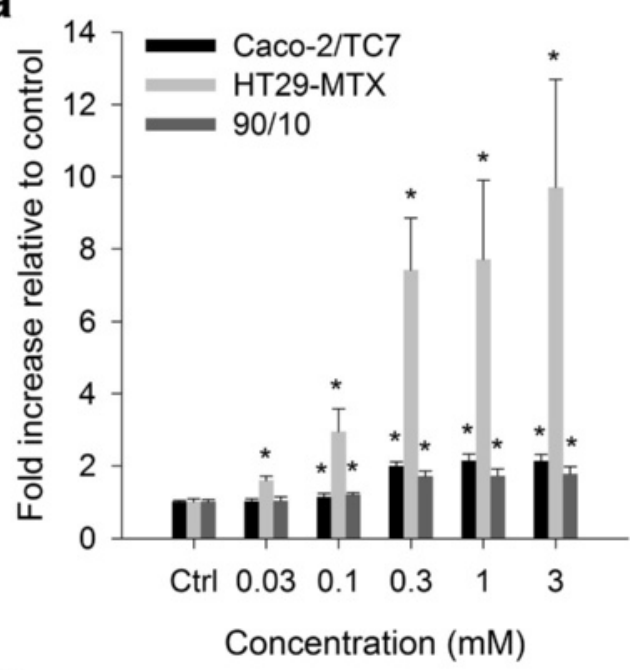

b

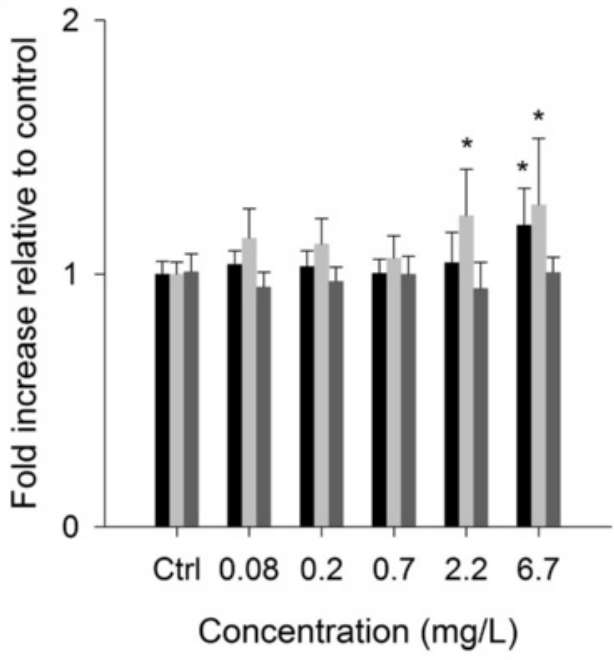

C

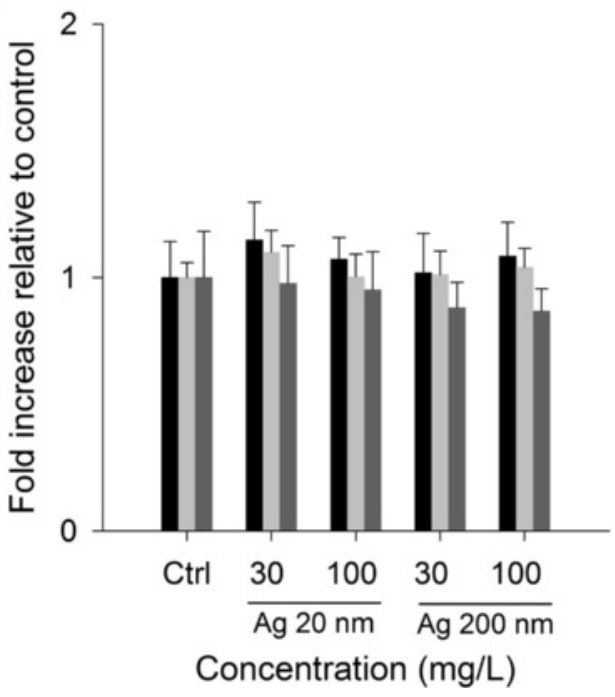

Fig. 3 Intracellular reactive oxygen species formation. Effect of (a) $\mathrm{H}_{2} \mathrm{O}_{2}$ (positive control), (b) $\mathrm{AgNO}_{3}$ and (c) $\mathrm{Ag} 20$ and $200 \mathrm{~nm}$ particles on the reactive oxygen species formation. After 14 days in culture Caco-2/TC7, HT29-MTX and the 90:10 co-culture were exposed for $2 \mathrm{~h}$. Error bars represent the mean \pm SD of 3 independent experiments performed in triplicate. Significant differences from respective untreated controls are marked with asterisks ( ${ }^{*}$ for $\left.P<0.05\right)$

$200 \mathrm{~nm} \mathrm{Ag}$ particles which was further confirmed by ICP-MS quantification (Additional file 1: Table S2). The TEM analysis (Additional file 1: Figure S6) showed internalization of particles close to the cell membrane that further confirms the NanoSIMS data. In the case of $\mathrm{Ag}$ $200 \mathrm{~nm}$ exposed cells, particles were particularly found in the brush border. However, according to NanoSIMS analysis, Ag was observed in proximity of the nuclei, supporting the idea that "hot spots" could be mainly represented by ions, rather than NPs.

Interactions with serum proteins are to be expected and it has been shown that the fetal bovine serum (FBS) content of the medium influenced the extent of NPs' uptake and toxic effects. In medium with $1 \%$ FBS a concentration and size-dependent cytotoxicity of $\mathrm{SiO}_{2} \mathrm{NPs}$ was observed while no cytotoxicity was reported in the $10 \%$ FBS-containing medium [30]. In our study $10 \%$ FBS was used which is the minimum content required for optimal growth and function of the Caco-2/TC7 and HT29-MTX cells. It has been reported that the rapid formation of protein corona led to an increase in the particle attachment to the cell surface and uptake and the particle type, surface functionalization and size affect the formation and composition of the corona [31]. The extent of Ag NPs' surface interaction with the proteins is still unknown but complexation processes are to be expected that could be size-dependent. The zeta potential of both particles in culture medium with $10 \%$ FBS was very similar and slightly negatively charged $(-13 \mathrm{mV})$. Therefore, the differences in uptake observed in our study cannot be explained solely by the charge differences of the particles. The proteins present in the cell culture medium containing FBS differ significantly from the proteins found in the biological fluids in vivo, therefore the uptake, bioavailability and translocation of the particles may differ in vivo. A study using an in vitro model for gastrointestinal digestion showed that Ag NPs form clusters after gastric digestion that disintegrate resulting in the reappearance of particles after intestinal digestion in the presence of proteins suggesting that NPs can reach the intestinal epithelium [32].

Although oxidative stress is one of the proposed mechanisms for NP toxicity, the studied Ag NPs did not lead to a significant increase in intracellular ROS formation which is in agreement with previous studies using Caco-2 [5] and BEAS-2B cells [33]. The cells in co- 


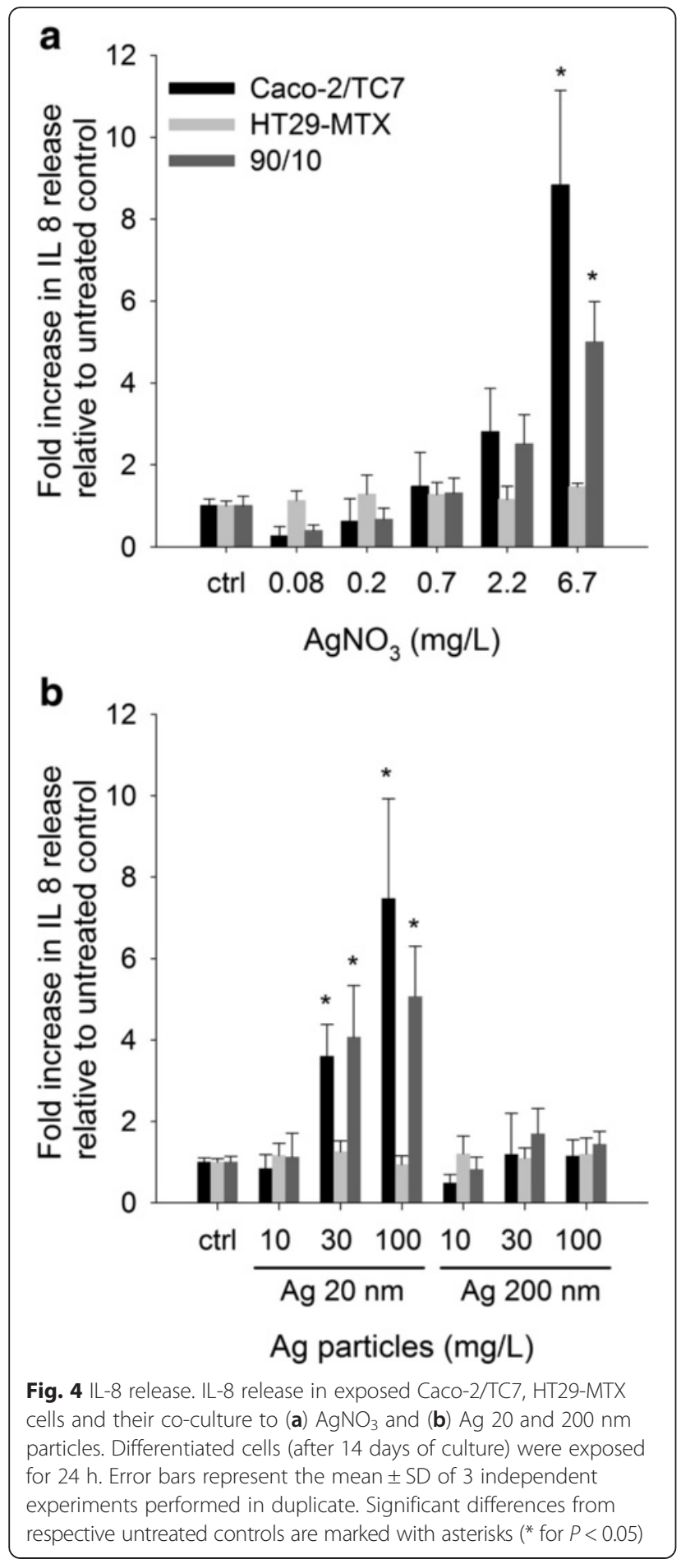

culture were less responsive to oxidative stress induced by $\mathrm{H}_{2} \mathrm{O}_{2}$ compared to Caco-2/TC7 cells alone. It has been previously shown that the mucus layer has ROS scavenging abilities and resists to ROS attack while low levels of ROS increase the barrier protection by increasing the mucus layer thickness [34]. Therefore, it seems reasonable to hypothesize that the presence of the mucus layer provides protection against ROS damage.

A significant size-dependent increased IL-8 release was observed with the smaller Ag $20 \mathrm{~nm}$ eliciting an 8 and 4 times higher inflammatory response compared to the larger Ag $200 \mathrm{~nm}$ in Caco-2/TC7 cells alone and the co-culture, respectively. This is in accordance with previous findings using the same set of NPs where only $20 \mathrm{~nm} \mathrm{Ag} \mathrm{NPs} \mathrm{up-regulated} \mathrm{the} \mathrm{IL-8} \mathrm{expression} \mathrm{[35].} \mathrm{A}$ possible explanation for this effect could be that bigger particles have different transport rates and are better retained in the mucus layer than smaller ones or ions that may thus cross the mucus layer and reach the cells faster and induce stronger effects. This could also mean that the protective effect of the mucus against $\mathrm{AgNO}_{3}$ could be rather limited. This correlates with the higher $\mathrm{Ag}$ concentrations (2.5 times higher) found for $\mathrm{Ag}$ $200 \mathrm{~nm}$ particles compared to $\mathrm{Ag} 20 \mathrm{~nm}$ in the coculture while the Ag signal observed in NanoSIMS was similar for both treatments suggesting that the biggersized particles are trapped in the mucus layer or are moving at a slower rate. Moreover, according to the TEM images Ag particles from the Ag $200 \mathrm{~nm}$ exposed cells are present in the brush border. A size dependency in the transit rate of NPs has been previously shown with smaller-sized particles showing a higher transit rate [29]. Thus, the immobilization of the bigger sized particles due to size exclusion by the mucus could result to reducing their interaction with the cellular membranes, the minor toxicity, low ROS levels and IL-8 release and decreased alterations at the proteome level observed in this study.

In order to have a comprehensive understanding of changes that occur upon $\mathrm{Ag} 20, \mathrm{Ag} 200 \mathrm{~nm}$ and $\mathrm{AgNO}_{3}$ exposure in the co-culture model, a proteomic study was included. The biggest changes in protein expression were induced by Ag $20 \mathrm{~nm}$ (50 differentially regulated proteins) followed by $\mathrm{AgNO}_{3}$ (16 modified proteins), while treatment with Ag $200 \mathrm{~nm}$ NPs only induced changes to 6 cytosolic proteins.

Ag $20 \mathrm{~nm}$ triggered an up-regulation of the cytoskeleton proteins cytokeratin 8 (CK8) and cytokeratin 18 (424 AA) (CK18) that are essential for the integrity of the epithelial cells [36]. They are co-expressed in a variety of tissues including the gastrointestinal tract [37] playing an important role in maintaining barrier function under stress. CK8/CK18 have been reported to be involved in IL-6 mediated barrier protection [38]. In addition, actin, cytoplasmic 1 (ACTB) that is essential for maintaining the epithelial integrity and regulating the structure of tight junctions [39, 40] was downregulated in $\mathrm{Ag} 20 \mathrm{~nm}$-exposed cells while higher levels were found for the liver type fatty acid-binding protein-1 (FABPL), that regulates absorption and transport of fatty acids [41] and has been reported to be a marker of 


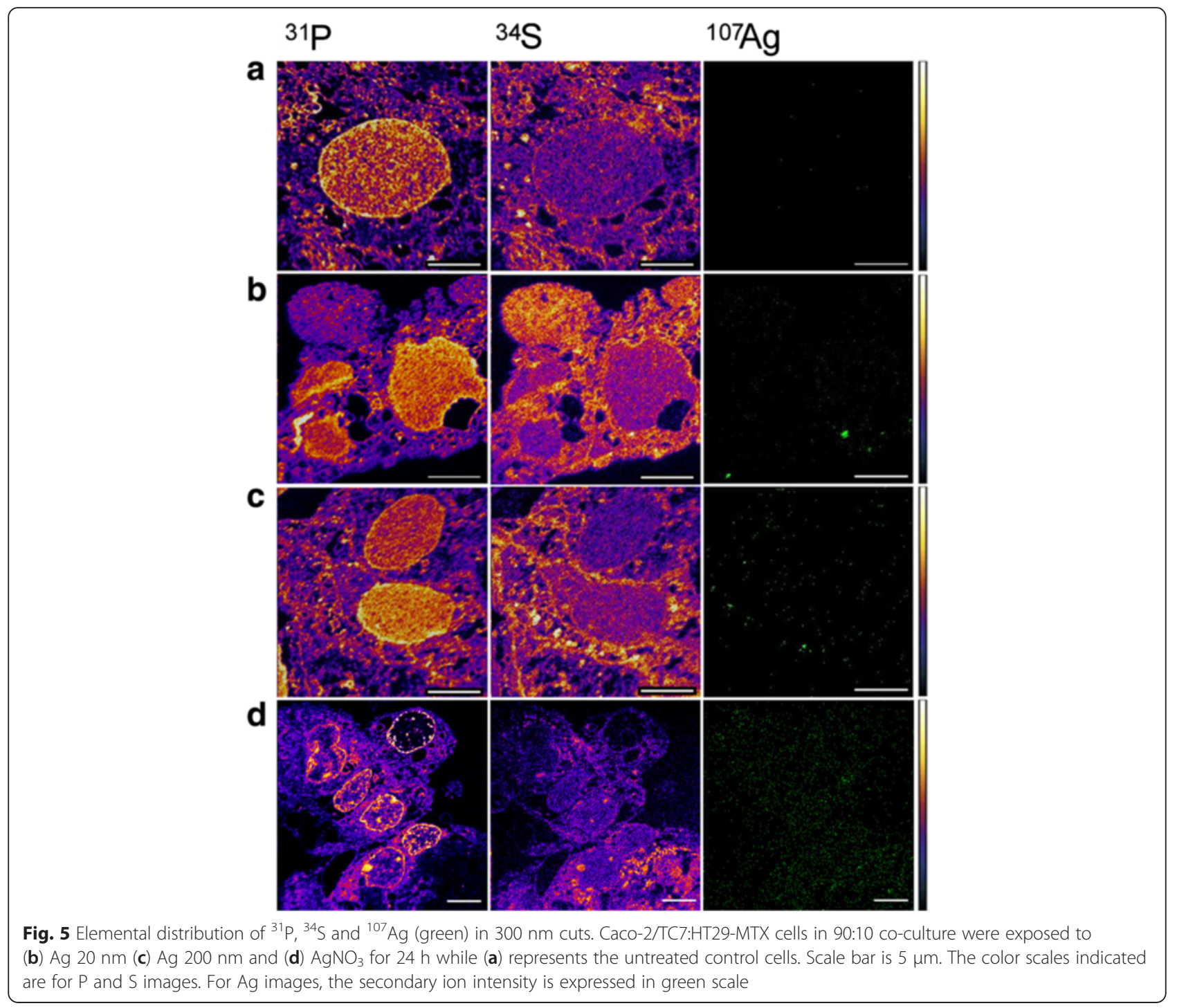

intestinal tissue injury [42]. Only the exposure to $\mathrm{Ag}$ $20 \mathrm{~nm}$ led to lower levels of chloride intracellular channel protein 1 (CLIC1) that is expressed in the apical part of columnar epithelia including the small intestine [43] and has been suggested to be associated with actin cytoskeleton [44]. It has been previously shown that CLIC1 is involved in cell cycle regulation and cell division and the over-expression of CLIC1 led to the inhibition of the proliferation of gastric cells and apoptosis induction [45]. In addition, the role of CLIC1 as a sensor of cell oxidation has been previously reported [46], which could suggest protection against apoptosis or response to oxidative conditions. The paracellular permeability, however, was not changed upon exposure to Ag NPs as measured with a paracellular permeability marker (lucifer yellow) and transepithelial electrical resistance (TEER) (Additional file 1: Figure S4).
Furthermore, higher levels of sialic acid synthase (SAS, also known as $\mathrm{N}$-acetylneuraminate synthase) were observed in Ag $20 \mathrm{~nm}$-treated cells. Sialic acids may have a structural role due to their presence in the outer surface of the cell and their negative charge and they are part of binding and recognition sites for pathogens and toxins [47] as well as they may mask recognition sites such as antigenic sites [48]. In addition, sialic acids are also localized in mucus glycoprotein and they contribute to the high viscosity of the mucus barrier and are of high importance for the maintenance of mucosal integrity [49]. An increased mucus production has been previously observed upon inflammatory conditions [29] and the higher levels of SAS observed in our study can be related to changes in mucus production in response to the increased IL-8 levels. The increased IL-8 levels observed in our study upon $\mathrm{Ag} 20 \mathrm{~nm}$ and $\mathrm{AgNO}_{3}$ and exposure 
Table 2 Proteins with altered abundance. The cells in co-culture were exposed to the non-toxic concentration of $1 \mathrm{mg} / \mathrm{L}$ of Ag $20 \mathrm{~nm}$ NPs, Ag $200 \mathrm{~nm}$ NPs or AgNO

\begin{tabular}{|c|c|c|c|c|c|c|c|c|c|c|c|c|c|c|c|c|}
\hline \multirow{2}{*}{$\begin{array}{l}\text { Spot } \\
\mathrm{N}^{\circ}\end{array}$} & \multirow[t]{2}{*}{ Protein name } & \multirow{2}{*}{$\begin{array}{l}\text { UniProt } \\
\text { Ac. } \mathrm{N}^{\circ}\end{array}$} & \multirow[t]{2}{*}{ UniProt ID } & \multirow[t]{2}{*}{ NCBI Gl } & \multirow{2}{*}{$\begin{array}{l}\text { Cov. } \\
\%\end{array}$} & \multirow{2}{*}{$\begin{array}{l}\text { MOWSE } \\
\text { Score }\end{array}$} & \multirow[t]{2}{*}{$\mathrm{p}$-value } & \multirow{2}{*}{$\begin{array}{l}\text { Queries } \\
\text { matched }\end{array}$} & \multirow{2}{*}{$\begin{array}{l}\mathrm{Mr} \\
(\mathrm{Da})\end{array}$} & \multirow{2}{*}{$\begin{array}{l}\mathrm{pl} \\
(\mathrm{pH})\end{array}$} & \multicolumn{2}{|c|}{$\mathrm{AgNO}_{3}$ vs Control } & \multicolumn{2}{|c|}{ Ag $20 \mathrm{~nm}$ vs Control } & \multicolumn{2}{|c|}{ Ag $200 \mathrm{~nm}$ vs Control } \\
\hline & & & & & & & & & & & Fold Change & t-test & Fold Change & t-test & Fold Change & t-test \\
\hline & Cytoskeleton-associated proteins & & & & & & & & & & & & & & & \\
\hline 260 & villin-1 & P09327 & VILI_HUMAN & 194394237 & $40 \%$ & 153 & $2.7 e-010$ & 40 & 93093 & 5.99 & -1.13 & 0.351 & -1.03 & 0.792 & 1.55 & 0.047 \\
\hline 701 & keratin, type II cytoskeletal 8 & P05787 & K2C8_HUMAN & 4504919 & $64 \%$ & 274 & $2.2 e-022$ & 38 & 53671 & 5.52 & -1.29 & 0.451 & 2.05 & 0.026 & -1.97 & 0.12 \\
\hline 800 & keratin, type II cytoskeletal 8 & P05787 & K2C8_HUMAN & 4504919 & $67 \%$ & 345 & $1.7 \mathrm{e}-029$ & 43 & 53671 & 5.52 & 1.13 & 0.468 & 1.7 & 0.002 & 1.16 & 0.18 \\
\hline 1083 & keratin, type II cytoskeletal 8 & P05787 & K2C8_HUMAN & 4504919 & $59 \%$ & 412 & $3.4 \mathrm{e}-036$ & 44 & 53671 & 5.52 & 3.1 & 0.001 & 1.59 & 0.022 & 1.1 & 0.598 \\
\hline 841 & cytokeratin 18 (424 AA) & P05783 & K1C18_HUMAN & 30311 & $77 \%$ & 387 & $1.1 \mathrm{e}-033$ & 46 & 47305 & 5.27 & 1.1 & 0.502 & 1.49 & 0.029 & 1.02 & 0.802 \\
\hline 263 & gelsolin isoform a precursor & B7Z9A0 & B7Z9AO_HUMAN & 221045118 & $35 \%$ & 130 & $5.4 \mathrm{e}-008$ & 34 & 83451 & 5.58 & -1.1 & 0.751 & 1.77 & 0.033 & 1.33 & 0.218 \\
\hline 984 & actin, cytoplasmic 1 & P60709 & ACTB_HUMAN & 14250401 & $72 \%$ & 527 & $1.1 e-047$ & 38 & 41321 & 5.56 & -1.1 & 0.114 & -1.74 & 0.004 & -1.05 & 0.282 \\
\hline 993 & actin, cytoplasmic 1 & Q53G99 & Q53G99_HUMAN & 62897625 & $85 \%$ & 642 & $3.4 e-059$ & 42 & 42080 & 5.37 & -1.22 & 0.083 & -1.94 & 0.001 & -1.1 & 0.319 \\
\hline 683 & tubulin alpha-1B chain & P68363 & TBA1B_HUMAN & 119578453 & $60 \%$ & 317 & $1.1 \mathrm{e}-026$ & 30 & 46797 & 4.96 & -2.16 & 0.009 & -1.55 & 0.077 & 1.07 & 0.815 \\
\hline 713 & tubulin, beta $2 \mathrm{C}$, isoform CRA_b & Q8N6N5 & Q8N6N5_HUMAN & 119608775 & $55 \%$ & 272 & $3.4 e-022$ & 38 & 49250 & 4.88 & -3.8 & 0.003 & -1.22 & 0.331 & 1.32 & 0.267 \\
\hline \multirow[t]{2}{*}{538} & dihydropyrimidinase-related protein 2 & Q16555 & DPYL2_HUMAN & 4503377 & $62 \%$ & 347 & $1.1 \mathrm{e}-029$ & 40 & 62711 & 5.95 & -1.62 & 0.052 & 1.44 & 0.08 & 1.44 & 0.117 \\
\hline & Oxidative stress-associated proteins & & & & & & & & & & & & & & & \\
\hline 1492 & peroxiredoxin-6 & P30041 & PRDX6_HUMAN & 4758638 & $89 \%$ & 718 & 8.6e--067 & 46 & 25133 & 6.00 & -1.45 & 0.005 & -1.25 & 0.036 & -1.33 & 0.032 \\
\hline 627 & protein disulfide-isomerase A3 & P30101 & PDIA3_HUMAN & 220702506 & $58 \%$ & 271 & 4.3e-022 & 38 & 55328 & 5.61 & 1.1 & 0.383 & 2.01 & 0.004 & 1.38 & 0.038 \\
\hline 629 & protein disulfide-isomerase A3 & P30101 & PDIA3_HUMAN & 220702506 & $64 \%$ & 795 & $1.7 e-074$ & 43 & 54541 & 5.61 & 1.34 & 0.18 & 2.63 & 0.007 & 1.42 & 0.106 \\
\hline 635 & protein disulfide-isomerase A3 & P30101 & PDIA3_HUMAN & 220702506 & $63 \%$ & 645 & $1.7 e-059$ & 44 & 54541 & 5.61 & 1.32 & 0.146 & 2.53 & 0.003 & 1.22 & 0.2 \\
\hline 655 & $\begin{array}{l}\text { protein disulfide isomerase family } A \text {, } \\
\text { member } 3 \text {, isoform CRA_a }\end{array}$ & B3KQT9 & B3KQT9_HUMAN & 119597640 & $40 \%$ & 81 & 0.0039 & 21 & 54454 & 6.78 & 1.69 & 0.043 & 1.1 & 0.247 & -1.06 & 0.514 \\
\hline 765 & protein disulfide-isomerase A6 & Q15084 & PDIA6_HUMAN & 1710248 & $63 \%$ & 419 & $6.8 \mathrm{e}-037$ & 38 & 46512 & 4.95 & 1.32 & 0.118 & 1.52 & 0.04 & -1.11 & 0.618 \\
\hline 769 & protein disulfide-isomerase A6 & Q15084 & PDIA6_HUMAN & 1710248 & $63 \%$ & 467 & $1.1 \mathrm{e}-041$ & 43 & 46512 & 4.95 & 1.25 & 0.104 & 1.53 & 0.02 & 1.05 & 0.757 \\
\hline \multirow[t]{2}{*}{767} & glutathione synthetase & P48637 & GSHB_HUMAN & 4504169 & $70 \%$ & 580 & $5.4 \mathrm{e}-053$ & 50 & 52523 & 5.67 & -1.08 & 0.367 & 1.48 & $9 E-04$ & 1.01 & 0.79 \\
\hline & Apoptosis-associated proteins & & & & & & & & & & & & & & & \\
\hline 1203 & annexin A4 & P09525 & ANXA4_HUMAN & 1703319 & $73 \%$ & 453 & $2.7 e-040$ & 39 & 36088 & 5.84 & -1.27 & 0.021 & -1.54 & 0.01 & -1.04 & 0.703 \\
\hline 1208 & annexin A4 & P09525 & ANXA4_HUMAN & 1703319 & $69 \%$ & 346 & $1.4 \mathrm{e}-029$ & 37 & 36088 & 5.84 & -1.16 & 0.434 & -1.1 & 0.611 & 1.88 & 0.009 \\
\hline 1226 & annexin A4 & P09525 & ANXA4_HUMAN & 1703319 & $73 \%$ & 731 & 4.3e-068 & 42 & 36088 & 5.84 & -1.24 & 0.119 & -1.63 & 0.006 & -1.06 & 0.676 \\
\hline 1769 & histidine triad nucleotide-binding protein 1 & P49773 & HINT1_HUMAN & 227968190 & $94 \%$ & 105 & $1.7 e-005$ & 18 & 13887 & 6.24 & 1.16 & 0.224 & 1.36 & 0.013 & 1.24 & 0.037 \\
\hline \multirow[t]{2}{*}{1773} & programmed cell death protein 5 & 014737 & PDCD5_HUMAN & 159163907 & $84 \%$ & 217 & $1.1 \mathrm{e}-016$ & 22 & 12911 & 9.85 & 1.72 & 0.011 & 1.03 & 0.896 & -1.45 & 0.115 \\
\hline & Stress-associated proteins & & & & & & & & & & & & & & & \\
\hline 408 & heat shock cognate $71 \mathrm{kDa}$ protein isoform 2 & Q53HF2 & Q53HF2_HUMAN & 24234686 & $57 \%$ & 419 & $6.8 \mathrm{e}-037$ & 39 & 53598 & 5.62 & -1.03 & 0.896 & 1.55 & 0.023 & -1.04 & 0.845 \\
\hline 414 & heat shock $70 \mathrm{kDa}$ protein $1 \mathrm{~A} / 1 \mathrm{~B}$ & P08107 & HSP71_HUMAN & 147744565 & $62 \%$ & 248 & 8.6e- 020 & 33 & 70294 & 5.48 & 1.46 & 0.016 & 1.57 & 0.017 & 1.1 & 0.493 \\
\hline 429 & heat shock $70 \mathrm{kDa}$ protein $1 \mathrm{~A} / 1 \mathrm{~B}$ & P08107 & HSP71_HUMAN & 147744565 & $56 \%$ & 515 & $1.7 e-046$ & 45 & 70294 & 5.48 & 1.33 & 0.01 & 1.61 & $3 E-04$ & 1.28 & 0.269 \\
\hline 438 & heat shock $70 \mathrm{kDa}$ protein $1 \mathrm{~A} / 1 \mathrm{~B}$ & P08107 & HSP71_HUMAN & 147744565 & $51 \%$ & 203 & $2.7 e-015$ & 31 & 70294 & 5.48 & 1.54 & 0.034 & 2.04 & 0.021 & 1.04 & 0.913 \\
\hline 573 & $60 \mathrm{kDa}$ heat shock protein, mitochondrial & P10809 & CH60_HUMAN & 31542947 & $53 \%$ & 357 & $1.1 \mathrm{e}-030$ & 43 & 61187 & 5.70 & -1.03 & 0.884 & 1.74 & 0.029 & -1.22 & 0.44 \\
\hline 576 & $60 \mathrm{kDa}$ heat shock protein, mitochondrial & P10809 & CH60_HUMAN & 31542947 & $45 \%$ & 138 & 8.6e-009 & 30 & 61187 & 5.70 & -1 & 0.86 & 1.75 & 0.004 & -1.15 & 0.356 \\
\hline
\end{tabular}


Table 2 Proteins with altered abundance. The cells in co-culture were exposed to the non-toxic concentration of $1 \mathrm{mg} / \mathrm{L} \mathrm{of} \mathrm{Ag} 20 \mathrm{~nm} \mathrm{NPs,} \mathrm{Ag} 200 \mathrm{~nm}$ NPs or AgNOa) (Continued)

\begin{tabular}{|c|c|c|c|c|c|c|c|c|c|c|c|c|c|c|c|c|}
\hline 577 & $60 \mathrm{kDa}$ heat shock protein, mitochondrial & P10809 & CH60_HUMAN & 31542947 & $57 \%$ & 641 & $4.3 e-059$ & 47 & 61187 & 5.70 & -1.04 & 0.889 & 1.85 & 0.048 & -1.21 & 0.577 \\
\hline 578 & $60 \mathrm{kDa}$ heat shock protein, mitochondrial & P10809 & CH60_HUMAN & 31542947 & $72 \%$ & 684 & $2.2 \mathrm{e}-063$ & 49 & 61187 & 5.70 & -1.04 & 0.869 & 1.66 & 0.067 & -1.26 & 0.469 \\
\hline 473 & stress-induced-phosphoprotein 1 & P31948 & STIP1_HUMAN & 5803181 & $54 \%$ & 131 & $4.3 e-008$ & 29 & 68721 & 7.81 & 1.05 & 0.57 & 2.02 & 0.002 & 1.37 & 0.012 \\
\hline \multirow[t]{2}{*}{479} & stress-induced-phosphoprotein 1 & P31948 & STIP1_HUMAN & 5803181 & $58 \%$ & 122 & $3.4 \mathrm{e}-007$ & 28 & 68721 & 7.81 & 1.08 & 0.404 & 2.03 & 0.003 & 1.29 & 0.032 \\
\hline & Metabolism-associated proteins & & & & & & & & & & & & & & & \\
\hline 625 & liver carboxylesterase 1 & P23141 & EST1_HUMAN & 30749518 & $45 \%$ & 133 & $2.7 \mathrm{e}-008$ & 38 & 60692 & 6.06 & -1.06 & 0.869 & -1.91 & 0.028 & -1.18 & 0.488 \\
\hline 631 & liver carboxylesterase 1 & P23141 & EST1_HUMAN & 30749518 & $51 \%$ & 109 & $6.8 \mathrm{e}-006$ & 31 & 60692 & 6.06 & -1.13 & 0.732 & -2.59 & 0.017 & -1.48 & 0.191 \\
\hline 1543 & glutathione $\mathrm{S}$-transferase $\mathrm{P}$ & P09211 & GSTP1_HUMAN & 4504183 & $75 \%$ & 716 & $1.4 \mathrm{e}-066$ & 29 & 23569 & 5.43 & -1.14 & 0.435 & -1.95 & 0.008 & -1.29 & 0.19 \\
\hline 1569 & glutathione S-transferase $P$ & P09211 & GSTP1_HUMAN & 4504183 & $75 \%$ & 681 & 4.3e-063 & 26 & 23569 & 5.43 & -1.03 & 0.791 & -1.68 & 0.008 & -1.17 & 0.266 \\
\hline 1866 & fatty acid binding protein & P07148 & FABPL_HUMAN & 182356 & $91 \%$ & 408 & $8.6 \mathrm{e}-036$ & 21 & 14226 & 6.60 & 1.26 & 0.195 & 1.88 & 0.008 & -1.07 & 0.706 \\
\hline 1177 & inorganic pyrophosphatase & Q15181 & IPYR_HUMAN & 11056044 & $77 \%$ & 234 & 2.2e-018 & 29 & 33095 & 5.54 & -1.16 & 0.332 & 1.41 & 0.05 & 1.2 & 0.366 \\
\hline 1199 & inorganic pyrophosphatase & Q15181 & IPYR_HUMAN & 11056044 & $68 \%$ & 169 & $6.8 \mathrm{e}-012$ & 25 & 33095 & 5.54 & -1.03 & 0.975 & 1.91 & 0.031 & 1.26 & 0.309 \\
\hline 1045 & sialic acid synthase & Q9NR45 & SIAS_HUMAN & 12056473 & $76 \%$ & 397 & $1.1 \mathrm{e}-034$ & 39 & 40738 & 6.29 & -1.15 & 0.548 & 1.58 & 0.046 & 1.37 & 0.109 \\
\hline 1133 & pyridoxal kinase & 000764 & PDXK_HUMAN & 119629883 & $45 \%$ & 123 & $2.7 e-007$ & 24 & 42931 & 7.59 & -1.06 & 0.702 & -1.7 & 0.008 & 1.01 & 0.988 \\
\hline 1320 & purine nucleoside phosphorylase & P00491 & PNPH_HUMAN & 157168362 & $73 \%$ & 244 & 2.2e-019 & 29 & 32758 & 6.71 & -1.25 & 0.249 & -2.03 & 0.028 & -1.18 & 0.405 \\
\hline 941 & aspartate aminotransferase, cytoplasmic & P17174 & AATC_HUMAN & 4504067 & $72 \%$ & 298 & $8.6 e-025$ & 39 & 46447 & 6.52 & 1.85 & 0.039 & 1.03 & 0.966 & 1.11 & 0.632 \\
\hline 1938 & polyubiquitin-C & $\mathrm{F} 5 \mathrm{H} 7 \mathrm{Y} 5$ & F5H7Y5_HUMAN & 228311825 & $80 \%$ & 556 & $1.4 \mathrm{e}-050$ & 24 & 17081 & 6.22 & 1.36 & 0.016 & 1.09 & 0.514 & -1.19 & 0.268 \\
\hline 185 & elongation factor 2 & P13639 & EF2_HUMAN & 4503483 & $37 \%$ & 197 & $1.1 \mathrm{e}-014$ & 38 & 96246 & 6.41 & 1.24 & 0.164 & -1.82 & 0.021 & 1.15 & 0.595 \\
\hline 200 & elongation factor 2 & P13639 & EF2_HUMAN & 4503483 & $46 \%$ & 258 & $8.6 \mathrm{e}-021$ & 45 & 96246 & 6.41 & -1.15 & 0.164 & -1.67 & 0.009 & 1.21 & 0.646 \\
\hline 1734 & peptidyl-prolyl cis-trans isomerase A & P62937 & PPIA_HUMAN & 1633054 & $93 \%$ & 443 & $2.7 e-039$ & 23 & 18098 & 7.82 & 1.78 & 0.05 & -1.48 & 0.037 & -1.27 & 0.125 \\
\hline 994 & leukocyte elastase inhibitor & P30740 & ILEU_HUMAN & 13489087 & $56 \%$ & 563 & $2.7 e-051$ & 39 & 42829 & 5.90 & -1.65 & 0.003 & -2 & 0.001 & -1.25 & 0.147 \\
\hline 1007 & leukocyte elastase inhibitor & P30740 & ILEU_HUMAN & 13489087 & $52 \%$ & 266 & $1.4 \mathrm{e}-021$ & 27 & 42829 & 5.90 & -1.65 & 0.02 & -1.75 & 0.009 & -1.39 & 0.151 \\
\hline 1020 & leukocyte elastase inhibitor & P30740 & ILEU_HUMAN & 13489087 & $56 \%$ & 662 & $3.4 \mathrm{e}-061$ & 39 & 42829 & 5.90 & -1.22 & 0.024 & -1.32 & 0.005 & 1.11 & 0.021 \\
\hline 703 & retinal dehydrogenase 1 & P00352 & AL1A1_HUMAN & 21361176 & $52 \%$ & 318 & 8.6e-027 & 45 & 55454 & 6.30 & -1.28 & 0.064 & -1.62 & 0.01 & 1.19 & 0.18 \\
\hline 815 & alpha-enolase & P06733 & ENOA_HUMAN & 203282367 & $78 \%$ & 531 & $4.3 e-048$ & 48 & 47350 & 6.99 & 1.07 & 0.614 & 1.92 & 0.008 & 1.12 & 0.479 \\
\hline 816 & alpha-enolase & P06733 & ENOA_HUMAN & 203282367 & $80 \%$ & 383 & $2.7 \mathrm{e}-033$ & 45 & 47350 & 6.99 & -1.03 & 0.803 & 1.54 & 0.008 & 1.05 & 0.737 \\
\hline 1426 & triosephosphate isomerase isoform 1 & P60174 & TPIS_HUMAN & 4507645 & $97 \%$ & 631 & $4.3 e-058$ & 51 & 26938 & 6.45 & 1.13 & 0.515 & 1.95 & 0.025 & 1.09 & 0.582 \\
\hline 1443 & triosephosphate isomerase isoform 1 & P60174 & TPIS_HUMAN & 4507645 & $94 \%$ & 830 & $5.4 \mathrm{e}-078$ & 53 & 26938 & 6.45 & -1.02 & 0.946 & 1.92 & 0.049 & 1.18 & 0.501 \\
\hline 1461 & triosephosphate isomerase isoform 1 & P60174 & TPIS_HUMAN & 66360365 & $55 \%$ & 171 & 4.3e-012 & 26 & 26938 & 6.45 & -1.56 & 0.033 & -1.08 & 0.667 & -1.13 & 0.494 \\
\hline \multirow[t]{2}{*}{1008} & fructose-bisphosphate aldolase C & P09972 & ALDOC_HUMAN & 61680382 & $61 \%$ & 138 & 8.6e-009 & 23 & 37940 & 6.67 & -1.23 & 0.047 & -1.07 & 0.334 & 1.35 & 0.003 \\
\hline & Others & & & & & & & & & & & & & & & \\
\hline 1357 & chloride intracellular channel protein 1 & O00299 & CLIC1_HUMAN & 14251209 & $81 \%$ & 322 & $3.4 \mathrm{e}-027$ & 31 & 27248 & 5.09 & 1.2 & 0.107 & -1.55 & 0.009 & -1.2 & 0.064 \\
\hline 1370 & chloride intracellular channel protein 1 & 000299 & CLIC1_HUMAN & 14251209 & $75 \%$ & 506 & $1.4 \mathrm{e}-045$ & 38 & 27248 & 5.09 & -1.04 & 0.808 & -1.65 & 0.013 & -1.22 & 0.213 \\
\hline
\end{tabular}

a)The spot number; protein name; UniProt accession number; UniProt ID; NCBI accession number; sequence coverage; MOWSE score; p-value relative to the MASCOT identification; number of queries matched; theoretical molecular weight (expressed in Da) and isoelectric point (expressed in $\mathrm{pH}$ units); the fold change and relative t-test value for co-cultures treated with $\mathrm{AgNO}_{3}, \mathrm{Ag} 20 \mathrm{~nm} \mathrm{NPs}$ and $\mathrm{Ag} 200 \mathrm{~nm} \mathrm{NPs}_{\text {, }}$ respectively, are reported for each protein. Italics = protein is more abundant; Bold = protein is less abundant. 


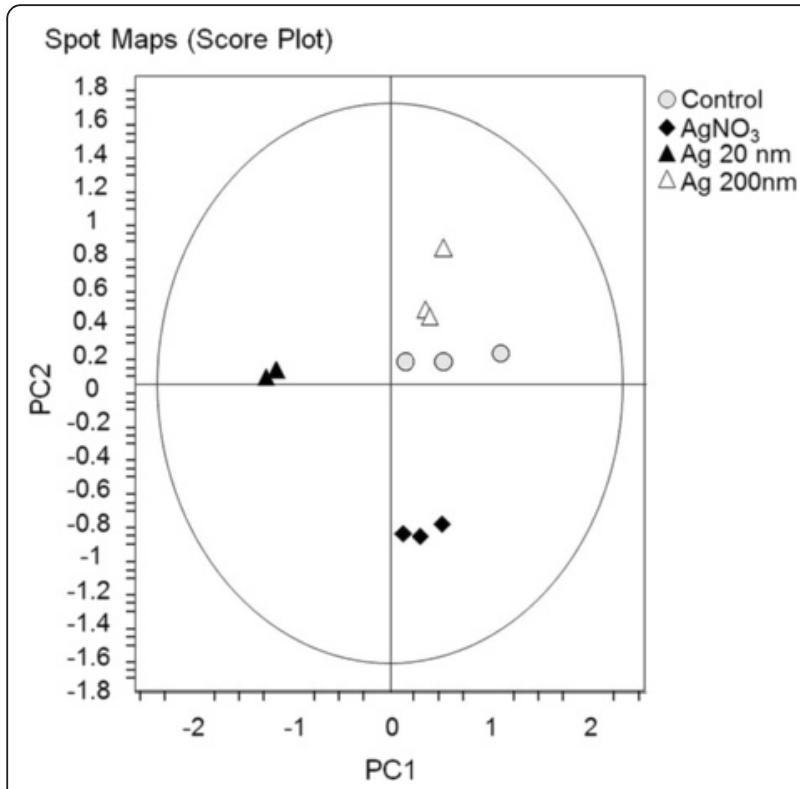

Fig. 6 Principal component analysis of differentially expressed proteins. Caco-2/TC7:HT29-MTX cells in 90:10 co-culture were exposed to $1 \mathrm{mg} / \mathrm{L}$ of $\mathrm{Ag} 20 \mathrm{~nm}, \mathrm{Ag} 200 \mathrm{~nm}$ or $\mathrm{AgNO}_{3}$ for $24 \mathrm{~h}$

can also be related to the changes observed in purine nucleoside phosphorylase (PNP) and peptidyl-prolyl cistrans isomerase A (PPIA), also known as cyclophilin A (CypA), respectively. PNP deficiency has been associated with immune dysfunction [50,51]. CypA can be released in the presence of inflammatory stimuli and it has been involved in several diseases (e.g. cardiovascular and inflammatory diseases, cancer) and plays a role in the regulation of infection and replication of several viruses [52]. CypA overexpression has been related with increased IL-8 levels and proliferation [53] as well as increased drug resistance [54].

Both Ag $20 \mathrm{~nm}$ (less abundant) and Ag $200 \mathrm{~nm}$ treatment (more abundant) led to altered levels of Annexin A4 (ANXA4), a key apoptosis regulator, that was suggested to be an early marker of apoptosis [55]. In the intestine, ANXA4 is present in both mature villus enterocytes (along the basolateral membrane) and goblet cells [56]. Moreover, higher levels of histidine triad nucleotide-binding protein 1 (HINT1) in Ag $20 \mathrm{~nm}$ treated cells were also observed that is involved in apoptotic processes and may also have tumor suppressor functions [57]. These results suggest that Ag NPs treatment affects apoptotic signaling in cells. The balance in cell proliferation and apoptosis is essential in the gastrointestinal epithelium for the maintenance of the normal function as a barrier [58].

A clear particle-size effect on the proteins that were differentially expressed was seen, that was also different from the pattern observed for $\mathrm{AgNO}_{3}$, which is in accordance with a recent study showing that particles of different sizes regulate different sets of proteins [12]. This is particularly visible from the multivariate analysis that was performed on the set of altered proteins (Fig. 6): the PCA clearly showed that Ag $200 \mathrm{~nm}$ treated co-culture cluster together with the untreated cells, while $\mathrm{AgNO}_{3}$-treated and $\mathrm{Ag} 20 \mathrm{~nm}$-treated co-cultures cluster away from the control and from each other. This could mean that the toxicity at a protein level is different for particles and soluble $\mathrm{Ag}\left(\mathrm{AgNO}_{3}\right)$ and that different sized particles induce different effects. Similar findings have been observed in a proteomic study of the plant Eruca sativa after exposure to either ionic or particulate silver indicating that the effects of $\mathrm{Ag}$ NPs are not due to ion release [59]. These results are in agreement with the IL-8 release findings and with a recent study with LoVo human colon cancer cells showing that more proteins were differentially regulated after exposure to Ag $20 \mathrm{~nm}$ than $\mathrm{Ag} 100 \mathrm{~nm}$ NPs regulating different sets of proteins [12]. Also in HepG2 cells exposed to the same Ag $200 \mathrm{~nm}$ particles, only minor changes in gene expression were found [35].

$\mathrm{Ag} 20 \mathrm{~nm}$ altered the expression of proteins that play an important role in xenobiotic metabolism probably compromising the detoxification process. The protein liver carboxylesterase 1 (CES1), responsible for the hydrolysis and metabolism of endogenous and exogenous compounds [60], and glutathione S-transferase P (GSTP1) were found to be less abundant in the Ag $20 \mathrm{~nm}$-treated cells in co-culture. GSTP1 belongs to the family of phase II detoxification enzymes, responsible for the metabolism of xenobiotics and secondary metabolites/by-products of oxidative stress [61].

Normally cells have a defense system against oxidative stress with a variety of enzymes being involved. Both Ag NPs treatments and $\mathrm{AgNO}_{3}$ triggered a down-regulation of peroxiredoxin-6 (PRDX6, the only overlap observed for all treatments) that is a member of peroxiredoxins and is involved in redox regulation of the cell and protection against oxidative injury [62]. A previous suppression of PRDX6 led to increased ROS levels and apoptosis of cancer cells [63]. This implies that both Ag NPs and ions lead to a compromised oxidative defense system. Ag $20 \mathrm{~nm}$ activated proteins related to redox homeostasis. Increased levels of protein disulfide isomerases A3 and A6 (PDIA3 and PDIA6) were observed in Ag $20 \mathrm{~nm}$-treated cells. Thus, the increased levels observed could counteract the effects induced by oxidative stress such as protein misfolding or damage. In addition, Ag $20 \mathrm{~nm}$ treatment led to increased levels of glutathione synthetase (GSS) that is critical for the synthesis of glutathione (GSH), a major anti-oxidant and detoxification agent [64] that provides defense against metabolite toxicity [65]. Therefore, these results indicate that both Ag NPs and $\mathrm{AgNO}_{3}$ but mainly $\mathrm{Ag} 20 \mathrm{~nm}$, lead to the 


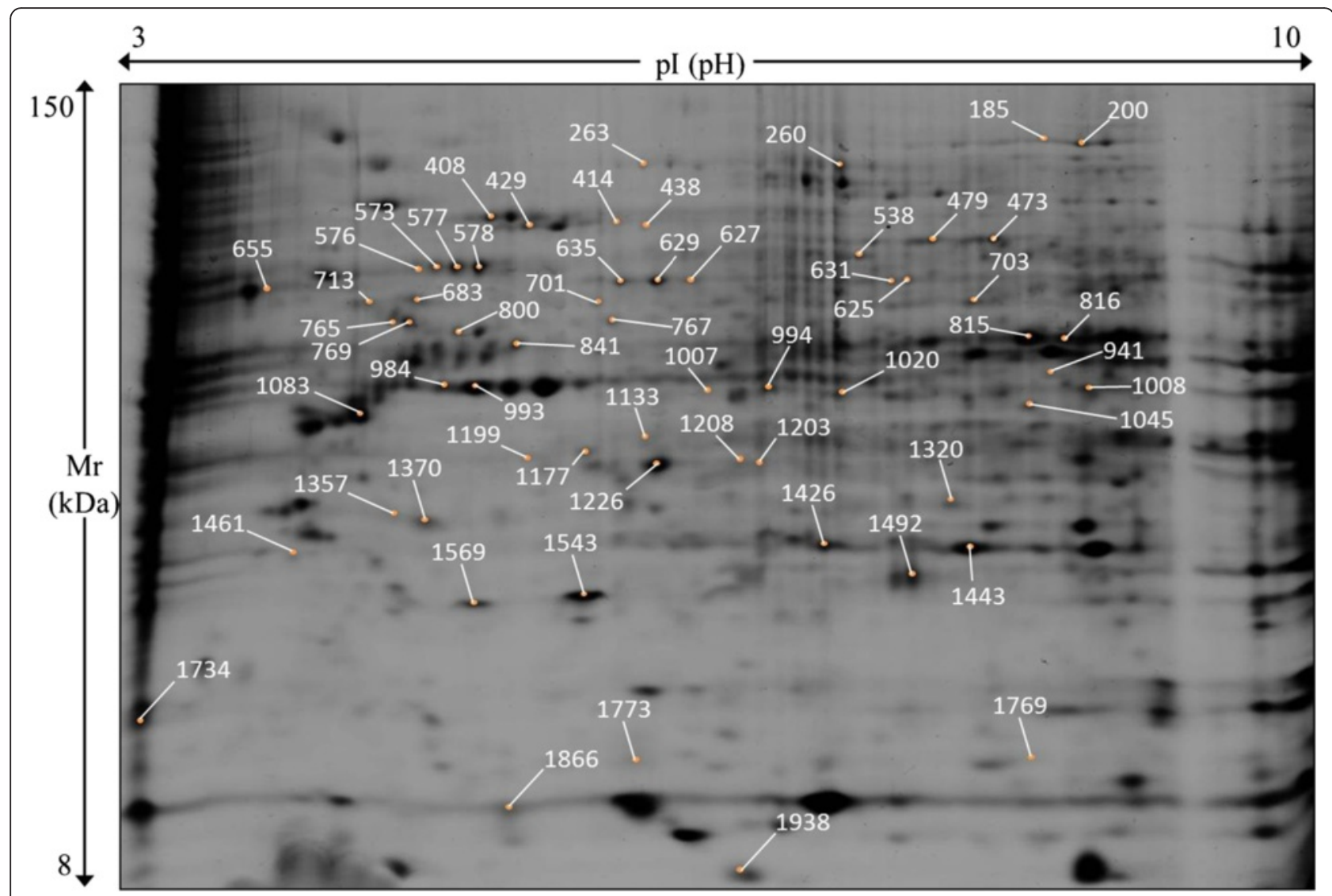

Fig. 7 A representative 2D-DIGE gel. Caco-2/TC7:HT29-MTX cells in 90:10 co-culture were exposed to 1 mg/L of Ag NPs 20 nm, 200 nm or AgNO for $24 \mathrm{~h}$ prior to protein extraction. Cytosolic proteins were separated in first dimension on $24 \mathrm{~cm}$ strips, $\mathrm{pH}$ 3-10 non-linear and in second dimension on a $12.5 \%$ polyacrylamide precast gel. Yellow dots indicate picking location on the gels. For each spot the relative spot number is reported

activation of mechanisms in order to deal with oxidative stress and maintain cellular homeostasis.

The list of altered proteins triggered by Ag NPs was subjected to KEGG enrichment analysis (performed with the EDA module in the Decyder software), with the aim of identifying altered cellular pathways. The analysis highlighted that a number of pathways seems to be affected by the treatment and in particular these are involved, along with metabolic pathways, oxidative stress pathways and protein processing pathways, in pathways related to pathogen invasion (e.g antigen presenting pathway and legionellosis). These pathways contribute to the inflammatory responses (e.g. IL-8 release) and suggest that the cell might detect the NPs as a pathogen. It has to be noted that the number of proteins included in the KEGG enrichment analysis was quite limited, thus these results should be carefully considered and validated with further studies.

In the current study, the proteomic results revealed an altered expression of proteins related to the maintenance of the redox balance of the cell, protection against oxidative damage and apoptosis as well as tissue damage and adaptation. The mechanisms of intestinal adaptation upon several internal and external stimuli involve altered expression levels of carrier proteins, changes in barrier permeability etc. [66] and proteins involved in the maintenance of the balance between cell proliferation and apoptosis which is a physiological event in the gastrointestinal epithelium. Our results revealed that $\mathrm{Ag}$ $20 \mathrm{~nm}$ NPs could result in a compromised intestinal barrier integrity and function as was shown with the increased levels of IL-8 as well as the altered levels of proteins that have been reported to be involved in intestinal injury and adaptation (e.g. ANXA4 and villin, CK8/ CK18, gelsolin, ACTB, IPYR, FABPL, SAS) that could have implications on the physiological processes occurring in the gastrointestinal epithelium such as normal nutrient absorption and transport as well as protection against pathogens and xenobiotics. In addition, Ag NPs $20 \mathrm{~nm}$ led to an up-regulation of several proteins (GSTP1, CES1, GSS) that together with the multidrug efflux transporters are involved in the defense of the 
cells against xenobiotics and metabolites in several tissues. Certain NPs can inhibit multidrug efflux transporters $[67,68]$ and this could possibly result in upregulation of compensation mechanisms.

\section{Conclusions}

The co-culture model represents a more physiological and relevant in vivo-like model compared to the Caco-2 cells alone, with the presence of mucus which has an impact on modulating the induced toxicity of NPs in a size dependent manner. The mucus layer presents a mechanical barrier mostly towards bigger sized particles reducing their interaction with the cellular membrane and subsequently leading to minor toxicity, reduced oxidative stress, IL- 8 release and proteomic alterations compared to $\mathrm{Ag} 20 \mathrm{~nm}$ particles and $\mathrm{AgNO}_{3}$. The proteomic results revealed that Ag NPs $20 \mathrm{~nm}$ regulated different sets of proteins with a distinct pattern of cellular responses compared to $\mathrm{Ag} 200 \mathrm{~nm}$ and $\mathrm{AgNO}_{3}$, indicating a different mode of action with effects being particle and size-dependent. The changes observed in the proteome level and the increased IL-8 levels indicate that Ag NPs trigger a pathogen-like response and the regulation of proteins responsible for the maintenance of the intestinal barrier function and integrity. Further research should elucidate the uptake mechanisms in the co-culture for different sized particles and ions, the role of mucus on the transit rate of the different-sized NPs and the mechanism leading to increased inflammatory response.

\section{Methods}

Ag NPs and chemicals

Ag NPs (20 and $200 \mathrm{~nm}$ ) were obtained from PlasmaChem $\mathrm{GmbH}$ (Berlin, Germany). Silver nitrate $\left(\mathrm{AgNO}_{3}\right)$ was purchased from VWR (Leuven, Belgium) and Alcian blue, $\mathrm{H}_{2} \mathrm{O}_{2}$, Toluidine blue, 2', $7^{\prime}$-dichlorofluorescin diacetate (DCFH-DA), osmium tetroxide $\left(\mathrm{OsO}_{4}\right)$, glutaraldehyde, resazurin sodium salt and the epoxy resin embedding kit from Sigma Aldrich (Bornem, Belgium). IL-8 kit was obtained from ENZO Life Sciences BVBA (Zandhoven, Belgium).

\section{Ag NPs dispersion protocols}

Ag NP stock solutions were prepared as previously described [69, 70]. Briefly, the Ag NPs were suspended in $5 \%$ DMSO in sterile Milli-Q water (Millipak Express, Millipore) at a concentration of $2 \mathrm{mg} / \mathrm{mL}$ and sonicated on ice for $3 \mathrm{~min}$ using a UP200S probe ultra sonicator ( 0.5 cycle, $30 \%$ amplitude, Hielscher, Germany). Stocks were always prepared fresh prior to each experiment. The characteristics of the NPs in different culture media can be found in previous studies [69-71].

\section{Ag NPs characterization in medium}

Dynamic light scattering and zeta $(\zeta)$ potential measurements of NPs in solution were carried out with a nanoZetasizer (Malvern Instruments Ltd, UK). The stocks were added to the full cell culture medium containing $10 \%$ FBS in order to achieve the highest concentration at which the cells were exposed $(100 \mathrm{mg} / \mathrm{L})$.

\section{Cell culture}

The human colon cancer Caco-2 cell line sub-clone TC7 (Caco-2/TC7) was a generous gift from Monique Rousset (Nancy University, France). HT29-MTX cells were kindly provided by T. Lesuffleur (INSERM UMR S 938, Paris, France). Phosphate Buffer Saline (PBS) and heatinactivated Fetal Bovine Serum (FBS) were all obtained from Invitrogen (Merelbeke, Belgium).

Both cell lines were maintained in Dulbecco's Modified Eagle Medium-Glutamax (DMEM-Glutamax, Invitrogen) supplemented with $10 \%$ fetal bovine serum, $1 \%$ non-essential amino acids and $1 \%$ penicillin/streptomycin solution (at $37{ }^{\circ} \mathrm{C}$ in a $10 \% \mathrm{CO}_{2}$ humidified incubator). The medium was replaced every other day and cells were split upon confluency with Trypsin-EDTA. In order to ensure full differentiation of cells, experiments were carried out 14 days post seeding.

\section{Metabolic activity assay (Alamar Blue) as a measure of cytotoxicity}

The single cell cultures of Caco-2/TC7, HT29-MTX and their co-culture at a 90:10 ratio were seeded at a concentration of $1.2 \times 10^{5}$ cells $/ \mathrm{mL}$ in 12 -well plates and were grown for 14 days at $37^{\circ} \mathrm{C}$ in a $10 \% \mathrm{CO}_{2}$ humidified incubator. After 14 days the medium was discarded and new medium containing increasing concentrations of the Ag NPs $(0-100 \mathrm{mg} / \mathrm{L})$ or $\mathrm{AgNO}_{3}(0-60 \mathrm{mg} / \mathrm{L})$ was added (serially diluted in complete medium). For the cell viability assay for $\mathrm{AgNO}_{3}$ a maximum concentration of $60 \mathrm{mg} / \mathrm{L}$ was chosen based on preliminary experiments, while the maximum concentration chosen for the preliminary screening on cell viability for Ag particles was $100 \mathrm{mg} / \mathrm{L}$. After $24 \mathrm{~h}$ of exposure, the medium containing the Ag NPs or $\mathrm{AgNO}_{3}$ was discarded and replaced with $1 \mathrm{~mL}$ of $500 \mu \mathrm{M}$ resazurin per well. Resazurin is a cell permeable, non-fluorescent compound that is reduced by metabolically active cells into the fluorescent resorufin. After $1.5 \mathrm{~h}$ of incubation at $37{ }^{\circ} \mathrm{C}$ in a $10 \%$ $\mathrm{CO}_{2}$ humidified incubator in the dark, fluorescence was measured at an excitation wavelength of $530 \mathrm{~nm}$ and emission wavelength of $590 \mathrm{~nm}$ (Synergy 2, BioTek Instruments, Inc.). The reported metabolic activity is expressed relative to the untreated group, which was set at $100 \%$.

For the following experiments, the concentrations were chosen based on the cell viability results. The 
highest concentrations that did not result in cell viability reduction are shown.

\section{Measurement of intracellular reactive oxygen species formation}

The levels of reactive oxygen species (ROS) were evaluated with the use of a non-fluorescent probe (DCFHDA) that once inside the cell it is deacetylated by cellular esterases into the non-fluorescent DCFH. When ROS are present $\mathrm{DCFH}$ is oxidized into the highly fluorescent DCF. The assay was optimized for the DCFH-DA concentration and the exposure time. The highest response to $\mathrm{H}_{2} \mathrm{O}_{2}$ and $\mathrm{Ag}$ was observed after $2 \mathrm{~h}$ of exposure and therefore this time point was chosen. Single cell culture of Caco-2/TC7 and HT29-MTX and their co-culture at a 90:10 ratio were seeded at a concentration of $1.2 \times 10^{5}$ cells/mL in 12-well plates and were grown for 14 days at $37{ }^{\circ} \mathrm{C}$ in a $10 \% \mathrm{CO}_{2}$ humidified incubator. After 14 days the medium was discarded and replaced with $1 \mathrm{~mL}$ of $150 \mu \mathrm{M}$ DCFH-DA per well. After $1 \mathrm{~h}$ of incubation at $37{ }^{\circ} \mathrm{C}$ in a $10 \% \mathrm{CO}_{2}$ humidified incubator in the dark, the dye was removed, the monolayers were washed with PBS and increasing concentrations of NPs or $\mathrm{AgNO}_{3}$ were added in the wells (serially diluted in cell culture medium). The highest concentration used for $\mathrm{AgNO}_{3}$ was $6.7 \mathrm{mg} / \mathrm{L}$ due to increased cytotoxicity. After $2 \mathrm{~h}$, fluorescence was measured at an excitation wavelength of $480 \mathrm{~nm}$ and emission wavelength of $530 \mathrm{~nm}$ (Synergy 2, BioTek Instruments, Inc.). As a positive control, $0.01 \%$ of $\mathrm{H}_{2} \mathrm{O}_{2}$ was included in every plate.

\section{Measurement of IL-8 release}

Caco-2/TC7, HT29-MTX cells or cells in co-culture at a 90:10 ratio were seeded at a concentration of $1.2 \times 10^{5}$ cells $/ \mathrm{mL}$ in 12 -well plates and were grown for 14 days at $37{ }^{\circ} \mathrm{C}$ in a $10 \% \mathrm{CO}_{2}$ humidified incubator. The medium was renewed every other day and after 14 days the medium was discarded and new medium containing increasing concentrations of the Ag NPs (0-100 mg/L) or $\mathrm{AgNO}_{3}$ (0-6.7 mg/L) was added (serially diluted in complete medium). The highest concentration used for $\mathrm{AgNO}_{3}$ was $6.7 \mathrm{mg} / \mathrm{L}$ due to increased cytotoxicity. At the end of the exposure period the supernatants were collected and stored at $-80{ }^{\circ} \mathrm{C}$ until analysis. The amount of IL-8 released upon exposure to $\mathrm{Ag} 20, \mathrm{Ag} 200 \mathrm{~nm}$ or $\mathrm{AgNO}_{3}$ for $24 \mathrm{~h}$ was evaluated with an enzyme-linked immunosorbent assay (ELISA) kit (Assay Designs/ENZO Life Sciences, Zandhoven, Belgium) according to the manufacturer's instruction protocol.

\section{Total soluble Ag release over time (Ultrafiltration and ICP-MS)}

The total amount of soluble Ag ionic species released from the Ag 20 and $200 \mathrm{~nm}$ particles in the cell culture medium was evaluated as previously described [69]. Briefly, $2 \mathrm{~mL}$ of exposure medium (medium + Ag NPs at the highest working concentration of $100 \mathrm{mg} / \mathrm{L}$ or only medium in the absence of cells) were taken after 6 and $24 \mathrm{~h}$ of incubation at $37{ }^{\circ} \mathrm{C}$ in a $10 \% \mathrm{CO}_{2}$ humidified incubator in the dark and were centrifuged for $40 \mathrm{~min}$ at $4000 \mathrm{~g}$ using centrifugal filter devices with $3 \mathrm{kDa}$ cut-off (Amicon ultra-4, Millipore, Ireland). The ultra-filtrates were evaluated for the total soluble Ag content by Inductively Coupled Plasma Mass Spectrometry (ICP-MS) (Elan DRC-e, Perkin Elmer, Waltham, MA, USA) as previously described $[69,72]$.

\section{Ag NP uptake evaluation in the co-culture (NanoSIMS50)}

The co-culture of Caco-2/TC7 and HT29-MTX at a 90:10 ratio was seeded in 12-well plates and after 14 days in culture the cells were exposed to $100 \mathrm{mg} / \mathrm{L} \mathrm{Ag} 20$ and $200 \mathrm{~nm}$ and $20 \mathrm{mg} / \mathrm{L} \mathrm{AgNO}_{3}$ for $24 \mathrm{~h}$. The cells were washed with PBS, detached with a cell scraper and transferred into eppendorf tubes. The settled cell pellets were fixed with $5 \%$ glutaraldehyde in PBS overnight. Glutaraldehyde was removed and cells were washed with PBS. They were then post fixed with $1 \% \mathrm{OsO}_{4}$ in milliQ water for $2 \mathrm{~h}$. After an additional washing step with PBS the cell pellets were placed in agar blocks ( $1 \%$ agar), they were dehydrated with increasing acetone concentrations (30, 50, 70, 90 and $100 \%$ acetone), and they were finally embedded in epoxy resin (Epon 812 substitute) in molds (easy molds, Ted Pella, Inc). Samples were cut to $300 \mathrm{~nm}$ semi-thin sections (Leica Ultracut UCT, Le Pecq Cedex, France) and deposited on silicon wafers (Siltronix, Archamps, France) for SIMS analysis. The NanoSIMS 50 [69, 73, 74] (Cameca, Courbevoie, France) analyses were performed by scanning of the surface $\left(40 \times 40 \mu \mathrm{m}^{2}\right.$ and $20 \times 20 \mu^{2}$ ) with a primary $\mathrm{Cs}^{+}$ion. The impact of the primary beam was $16 \mathrm{keV}$ with an intensity range of 1.0-0.8 pA. Images were recorded in a pixel format of $256 \times 256$ image points with a counting time of $20 \mathrm{~ms}$ per pixel. The probe-working diameter was estimated in the range of $80-100 \mathrm{~nm}$. The secondary negative ions recorded simultaneously were: ${ }^{12} \mathrm{C}^{14} \mathrm{~N}^{-}$ $(\mathrm{m}=26.00307 \mathrm{amu}),{ }^{31} \mathrm{P}^{-} \quad(\mathrm{m}=30.97376 \mathrm{amu}),{ }^{34} \mathrm{~S}^{-}$ $(\mathrm{m}=33.96786 \mathrm{amu})$ and ${ }^{107} \mathrm{Ag}^{-}(\mathrm{m}=106.90486 \mathrm{amu})$.

\section{Cellular Ag content determination}

Caco-2/TC7, HT29-MTX cells or cells in co-culture at a 90:10 ratio were seeded at a concentration of $1.2 \times 10^{5}$ cells $/ \mathrm{mL}$ in 12-well plates and were grown for 14 days at $37{ }^{\circ} \mathrm{C}$ in a $10 \% \mathrm{CO}_{2}$ humidified incubator. The medium was renewed every other day and after 14 days the medium was discarded and new medium containing $100 \mathrm{mg} / \mathrm{L} \mathrm{Ag} \mathrm{NPs} 20$ and $200 \mathrm{~nm}$ or $20 \mathrm{mg} / \mathrm{L} \mathrm{AgNO}_{3}$ was added. In addition, a treatment of the cells in coculture with $1 \mathrm{mg} / \mathrm{L} \mathrm{Ag} 20$ and $200 \mathrm{~nm}$ or $\mathrm{AgNO}_{3}$ was 
included. At the end of the exposure the cells were washed with PBS, they were detached with TrypsinEDTA and the cell pellet was collected after centrifugation at $1500 \mathrm{rpm}$ for $5 \mathrm{~min}$. The samples were digested in $3 \mathrm{~mL}$ demineralized water with $1.75 \mathrm{~mL} \mathrm{HNO}_{3}$ (min $67 \%$ for trace analysis, LGC Standards, Germany) and $0.75 \mathrm{~mL} \mathrm{H}_{2} \mathrm{O}_{2}$ (30 \% Suprapur, Merck, Germany). Then the volume was completed to $10 \mathrm{~mL}$ with demineralized water and the obtained solution was diluted 3 times with $1 \% \mathrm{HNO}_{3}$ before analysis. Silver was analyzed by Inductively Coupled Plasma Mass Spectrometry (ICP-MS).

\section{Proteomic approach}

The co-culture of Caco-2/TC7 and HT29-MTX cells at a 90:10 ratio was seeded in cell culture flasks (Nunclon, $175 \mathrm{~cm}^{2}$ ) at a concentration of $2.9 \times 10^{5}$ cells $/ \mathrm{mL}$ $\left(30 \mathrm{~mL} /\right.$ flask) and were grown for 14 days at $37^{\circ} \mathrm{C}$ in a $10 \% \mathrm{CO}_{2}$ humidified incubator with a medium change every other day. After 14 days the medium was discarded and replaced by new medium containing $1 \mathrm{mg} / \mathrm{L}$ Ag 20, Ag $200 \mathrm{~nm}$ or $\mathrm{AgNO}_{3}$ for $24 \mathrm{~h}$. This dose was selected in order to ensure that cytotoxicity would not affect the results. Four replicates per treatment were used including untreated/solvent control $(0.25 \%$ DMSO). At the end of the exposure period, the medium was removed and the monolayers were washed twice with $7 \mathrm{~mL}$ ice-cold PBS. Five $\mathrm{mL}$ of ice-cold PBS were added and the cell monolayers were detached using a cell scraper and transferred in a $15 \mathrm{~mL}$ falcon tube. After centrifugation for $5 \mathrm{~min}$ at $1500 \mathrm{rpm}$ at $4{ }^{\circ} \mathrm{C}$ (Beckman TM Allegra 64R Beckman Coulter, CA, U.S.) the supernatant was removed and the cells were stored at $-20{ }^{\circ} \mathrm{C}$ until protein extraction.

\section{Protein extraction}

The cells were re-suspended in a lysis buffer $(100 \mathrm{mM}$ PIPES, $70 \mathrm{mM} \mathrm{NaCl}$ ) supplemented with a protease inhibitor cocktail (Protease inhibitor mix, GE Healthcare, Little Chalfont, UK). The cellular pellets were disrupted by the use of the French Press cell disruptor (Thermo Electron Corporation, MA, U.S.) at a pressure of $200 \mathrm{psi}$. Total cellular lysates were collected and stored on ice. Subsequently, the lysate was pelleted at 2,100 rpm for 15 min at $4{ }^{\circ} \mathrm{C}$ using the Beckman TM Allegra 64R centrifuge on a F1010 rotor (Beckman Coulter, CA, U.S.) in order to remove nuclei from the supernatant.

The supernatant (containing all cellular fractions excluding the nuclei) was centrifuged at 20,000 rpm during 20 min at $4{ }^{\circ} \mathrm{C}$ in Beckman TM Optima TM L90K ultracentrifuge on a $45 \mathrm{Ti}$ rotor. This pellet consisted mainly of mitochondria and nucleus fragments. The supernatant was again centrifuged at $45,000 \mathrm{rpm}$ for $80 \mathrm{~min}$ at $4{ }^{\circ} \mathrm{C}$ using a Beckman TM Optima TM L90K ultracentrifuge on a $45 \mathrm{Ti}$ rotor. The proteins in this supernatant, consisting of soluble cytosolic proteins, were precipitated overnight with ice-cold acetone at $-20{ }^{\circ} \mathrm{C}$. After centrifugation for $10 \mathrm{~min}$ at $7,500 \mathrm{rpm}\left(4{ }^{\circ} \mathrm{C}\right.$ ) (Beckman $\mathrm{TM}$ Allegra 64R centrifuge on a F1010 rotor), the pellet of cytosolic proteins was dried under vacuum (SpeedVac, Thermo Fischer Scientific) and stored at $-20{ }^{\circ} \mathrm{C}$ until further analysis.

The cytosolic proteins were then solubilized in labeling buffer (7 M urea, $2 \mathrm{M}$ thiourea, $30 \mathrm{mM}$ Tris, $2 \%$ w/v 3[(3-cholamidopropyl)dimethylammonio]-1-propanesulfonate (CHAPS), $2 \% \mathrm{w} / \mathrm{v}$ 3-[N,N-Dimethyl(3-myristoylaminopropyl)ammonio]propanesulfonate (ASB14). After adjusting the $\mathrm{pH}$ of the sample solutions [ $\mathrm{pH} 8.5$ - 9], the protein concentrations were determined using the 2D Quant kit (GE Healthcare, UK) with bovine serum albumin $(2 \mathrm{mg} / \mathrm{mL})$ as standard.

\section{D-DIGE, imaging of gels and protein identification}

Cytosolic proteins were labeled with the CyDyes minimal labeling method (GE Healthcare, UK). 2D-DIGE separation, imaging of the gels, picking and identification of the spot of interest were carried out as described before with minor modifications $[75,76]$. The labeling was performed according to the manufacturer's instructions. Forty $\mu \mathrm{g}$ of cytosolic proteins were used for each sample and labeled using the CyDyes minimal labeling method (GE Healthcare, UK). The internal standard was constituted by an equal fraction of each sample included in the experiment in order to correct the quantification of the proteins for potential uneven loading and electrophoretic conditions. Briefly, each sample plus internal standard were individually labeled for $30 \mathrm{~min}$ on ice in the dark with 320 pmol of either Cy3, Cy5 (for the analytical samples) or Cy2 (for the internal standard). Labeling reaction was stopped by the addition of $1 \mu \mathrm{L} 10 \mathrm{mM}$ lysine solution and incubation for $15 \mathrm{~min}$ on ice in the dark. Labeled samples were pooled such that each pool contained an equal ratio of proteins marked with $\mathrm{Cy} 2$, Cy3, and Cy5: two samples of $40 \mu \mathrm{g}$ each (one labeled with $\mathrm{Cy} 3$ and one labeled with Cy5) and $40 \mu \mathrm{g}$ of internal standard were then mixed and their final volume was adjusted to $120 \mu \mathrm{L}$ using lysis buffer (7 M urea, $2 \mathrm{M}$ thiourea, $2 \% \mathrm{w} / \mathrm{v}$ CHAPS, $2 \% \mathrm{w} / \mathrm{v}$ ASB14). Prior to electrophoresis, ampholytes (Biolytes 3-10, $3 \% \mathrm{v} / \mathrm{v}$, BioRad, Belgium) and Destreak reagent $(0.6 \% \mathrm{v} / \mathrm{v}, \mathrm{GE}$ Healthcare, Belgium) were added to each tube.

Each pool was then loaded onto a strip for the isoelectric separation ( $1^{\text {st }}$ dimension). After re-hydration of the strips with $450 \mu \mathrm{L}$ of Destreak re-hydration solution (GE Healthcare) for at least $12 \mathrm{~h}$, the samples were directly applied on re-hydrated strips via sample loading cups. Separation was achieved using an Ettan IPGphor III (GE Healthcare) at $20{ }^{\circ} \mathrm{C}$ allowing the strip to reach a total electric current of $80 \mathrm{k}$ Vh in $25 \mathrm{~h}$. Following the $1^{\text {st }}$ 
dimension, proteins were reduced and alkylated by incubating the strip in two consecutive steps of $15 \mathrm{~min}$ at room temperature in an equilibration buffer (2DGel DALT, SERVA electrophoresis gmbh, Germany) containing 1 \% DTT (Sigma, Belgium) and $2.5 \%$ iodoacetamide (Sigma, Belgium), respectively. Equilibrated strips were orthogonally loaded on large format precast gels $(24 \mathrm{~cm}$ 2D DALT NF large gel $12.5 \%$, SERVA electrophoresis gmbh, Germany) using the Flap cassette system (sealed with agarose) and subjected to electrophoretic separation with an Ettan DALT XII system (GE Healthcare, Belgium) by applying $0.5 \mathrm{~W} /$ gel for $2 \mathrm{~h}$ and then then $2.5 \mathrm{~W} /$ gel for $14 \mathrm{~h}$ at $25^{\circ} \mathrm{C}$ ( $2^{\text {nd }}$ dimension). Acquisition of gel images was carried out using a Typhoon 9400 (GE Healthcare) at a special resolution of $100 \mu \mathrm{m}$. CyDyes were visualized using excitation at $488 \mathrm{~nm}, 532 \mathrm{~nm}$, and $633 \mathrm{~nm}$ (Cy2, Сy3 and Cy5, respectively) and emission at $520 \mathrm{~nm}, 610 \mathrm{~nm}$ and $670 \mathrm{~nm}$ (Cy2, Cy3 and Cy5, respectively). Gels were analyzed for the differentially abundant proteins by the DeCyder 2D Differential Analysis v.7.0 software package (GE Healthcare). Criteria for the selection were: spot present in at least $75 \%$ of the spot maps, fold change of at least \pm 1.3 , statistical significance $(P \leq 0.05)$.

\section{Protein identification by MALDI-TOF/TOF}

Spots of interest were used to generate a "pick list" which was submitted to the Ettan Spot Handling Workstation (GE Healthcare) for automatic picking, trypsin digestion and spotting of the peptides on the MALDI target plates with an equal volume of $\alpha$-cyano-4-hydroxy cinnamic acid (HCCA). On spots of interest a combined approach of protein mass fingerprint (PMF) and MS/MS using the Applied Biosystems MALDI-TOF/TOF 4800 Proteomics Analyser was applied. Calibration was carried out with the peptide mass calibration kit 4700 (Applied Biosystems, Belgium). For each spot PMF spectra were acquired and up to $8 \mathrm{MS} / \mathrm{MS}$ fragmentations were allowed on the most abundant precursors. Protein identification was achieved by searching the acquired spectra against the NCBInr database (version 20100924with 11888344 sequences; 4060865000 residues) with "Homo sapiens" as taxonomy (541459 sequences, downloaded on May 2011), using GPS Explorer Software v3.6 (Applied Biosystems) including MASCOT (Matrix Science, www.matrixscience. com, London, UK). Settings chosen for the dataset search were: $150 \mathrm{ppm}$ tolerance on PMF, $0.75 \mathrm{Da}$ tolerance for parent ion, up to two missed cleavages allowed, carboxyamidomethylation of cysteine as fixed modification, oxidation of methionine and oxidation of tryptophan (single oxidation, double oxidation and kynurenin) as variable modification. Proteins with probability-based MOWSE scores $(P<0.05)$ were considered to be positively identified.
Univariate statistical analysis and multivariate analysis, including principal component analysis (PCA) of differentially abundant proteins and KEGG enrichment analysis, were carried out using the EDA module which is present inside the Decyder 7.0 software package.

\section{Statistical analysis}

The data are expressed as mean values with standard deviations of three independent experiments each containing 3 replicates. Data were analyzed with SigmaPlot 12 (Systat Software, Inc. SigmaPlot for Windows) and SPSS (IBM SPSS Statistics for Windows, Version 21.0. Armonk, NY: IBM Corp) using a general linear model (univariate analysis) with a Tukey's post Hoc test for comparison of means. When necessary the data was transformed to achieve normal distribution and equal variances. Differences among means were considered to be significant at $P<0.05$.

\section{Additional file}

Additional file 1: Figure S1. Mucus layer characterization (Alcian blue staining). Figure S2. Mucus layer characterization (Toluidine blue staining and TEM). Figure S3. Mucus layer characterization (Toluidine blue staining, top view). Figure S4. Cell monolayer integrity evaluation (TEER). Figure S5. Cell-free DCFH-DA assay. Figure S6. TEM images of cells in co-culture exposed to Ag particles. Figure S7. Hierarchical clustering. Table S1. Detailed information on protein identification. Table S2. Cellular Ag content determination. Table S3. KEGG enrichment analysis. (DOCX $1.17 \mathrm{mb}$ )

\section{Abbreviations}

Ag NPs: Silver nanoparticles; DCFH-DA: Dichlorofluorescin diacetate; 2DDIGE: Two-dimensional difference in gel electrophoresis; DLS: Dynamic light scattering; FBS: Fetal bovine serum; ICP-MS: Inductively coupled plasma mass spectrometry; IL-8: Interleukine-8; ROS: Reactive oxygen species; MALDI-TOF/ TOF: Matrix assisted laser desorption ionization - Time of flight/ Time of flight; NanoSIMS: Secondary ion mass spectrometry; TEER: Transepithelial electrical resistance; TEM: Transmission electron microscopy.

\section{Competing interests}

The authors report no competing interests. The authors alone are responsible for the content and writing of the paper.

\section{Authors' contributions}

ACG and AG conceived and designed the experiments. AG, SC, JS and SC performed the experiments. EL, PG, JNA performed the NanoSIMS experiments. SE performed the TEM analysis. TS, CL and JR designed and performed the proteomics experiments. JZ and CG performed the ICP-MS experiments. AG wrote the paper. ACG, AJM, MK and LH performed critical revisions. All authors discussed and commented on the manuscript. All authors read and approved the final manuscript.

\section{Acknowledgements}

These experiments were supported by the Fonds National de la Recherche of Luxembourg within the projects NanEAU II (C10/SR/799842) and NANION (FNR/12/SR/4009651). Parts of the work have been performed in the framework of the "Small Particles-environmental behaviour and toxicity of nanomaterials and particulate matter" project. The authors would like to thank C. Carlson (Norwegian School of Veterinary Science, Oslo, Norway) and T.G. Iversen (The Norwegian Radium Hospital, Oslo, Norway) for their valuable help and advice on the size and zeta potential measurements. The work of A. El Moul (Materials Research and Technology Department, Luxembourg Institute of Science and Technology (LIST), Luxembourg) for sample cutting for NanoSIMS and TEM analyses is gratefully acknowledged. We also thank V. Peardon for editing the English of the manuscript. 


\section{Author details}

${ }^{1}$ Environmental Research and Innovation (ERIN) Department, Luxembourg Institute of Science and Technology (LIST), 5 avenue des Hauts-Forneaux, L-4362 Esch-sur-Alzette, Luxembourg. ${ }^{2}$ RIKILT- Institute of Food Safety, Wageningen UR, P.O. Box 230, NL-6700 AE Wageningen, The Netherlands. ${ }^{3}$ Faculty of Medicine, University of Information Technology and Management in Rzeszow, Sucharskiego 2, 35-225 Rzeszow, Poland. ${ }^{4}$ Centre for Radiobiology and Biological Dosimety, Institute of Nuclear Chemistry and Technology, Dorodna 16, 03-195 Warszawa, Poland. ${ }^{5}$ Materials Research and Technology Department (MRT), Luxembourg Institute of Science and Technology (LIST), 5 avenue des Hauts-Forneaux, L-4362 Esch-sur-Alzette, Luxembourg. 'Sub-department of Environmental Technology, Wageningen, The Netherlands. ${ }^{7}$ IMARES Wageningen UR Institute for Marine Resources \& Ecosystem Studies, P.O. Box 57, NL 1780 AB Den Helder, The Netherlands. ${ }^{8}$ Current address: Norwegian Institute for Water Research (NIVA), Gaustadalléen 21, NO-0349 Oslo, Norway.

Received: 5 March 2015 Accepted: 26 January 2016

Published online: 17 February 2016

\section{References}

1. Kruszewski M, Brzoska K, Brunborg G, Asare N, Dobrzynska M, Dusinska $\mathrm{M}$, et al. Toxicity of silver nanomaterials in higher eukaryotes. In Advances in Molecular Toxicology. Volume 5. Oxford UK: Elsevier B.V.; 2011:179-218

2. AshaRani PV, Low Kah Mun G, Prakash Hande M, Valiyaveettil S. Cytotoxicity and genotoxicity of silver nanoparticles in human cells. ACS Nano. 2009:3:279-90.

3. Bouwmeester $H$, Brandhoff $P$, Marvin HJP, Weigel S, Peters RJB. State of the safety assessment and current use of nanomaterials in food and food production. Trends Food Sci Technol. 2014;40:200-10.

4. Hoet PH, Brüske-Hohlfeld I, Salata OV. Nanoparticles - known and unknown health risks. J Nanobiotechnol. 2004;2:12.

5. Abbott Chalew TE, Schwab KJ. Toxicity of commercially available engineered nanoparticles to Caco-2 and SW480 human intestinal epithelial cells. Cell Biol Toxicol. 2013;29:101-16.

6. Bouwmeester H, Poortman J, Peters RJ, Wijma E, Kramer E, Makama S, et al. Characterization of translocation of silver nanoparticles and effects on whole-genome gene expression using an in vitro intestinal epithelium coculture model. ACS Nano. 2011;5:4091-103.

7. Böhmert L, Niemann B, Thünemann AF, Lampen A. Cytotoxicity of peptidecoated silver nanoparticles on the human intestinal cell line Caco-2. Arch Toxicol. 2012;86:1107-15.

8. Gaiser BK, Fernandes TF, Jepson MA, Lead JR, Tyler CR, Baalousha M, et al. Interspecies comparisons on the uptake and toxicity of silver and cerium dioxide nanoparticles. Environ Toxicol Chem. 2012;31:144-54.

9. Gerloff K, Pereira DIA, Faria N, Boots AW, Kolling J, Förster I, et al. Influence of simulated gastrointestinal conditions on particle-induced cytotoxicity and interleukin-8 regulation in differentiated and undifferentiated Caco-2 cells. Nanotoxicology. 2013;7:353-66.

10. Gerloff K, Albrecht C, Boots AW, Förster I, Schins RPF. Cytotoxicity and oxidative DNA damage by nanoparticles in human intestinal Caco-2 cells. Nanotoxicology. 2009;3:355-64

11. Piret J-P, Vankoningsloo S, Mejia J, Noël F, Boilan E, Lambinon F, et al. Differential toxicity of copper (II) oxide nanoparticles of similar hydrodynamic diameter on human differentiated intestinal Caco-2 cell monolayers is correlated in part to copper release and shape. Nanotoxicology. 2012;6:789-803.

12. Verano-Braga T, Miethling-Graff R, Wojdyla K, Rogowska-Wrzesinska A, Brewer JR, Erdmann $\mathrm{H}$, et al. Insights into the cellular response triggered by silver nanoparticles using quantitative proteomics. ACS Nano. 2014:8:2161-75

13. Stone $\mathrm{V}$, Johnston $\mathrm{H}$, Schins RPF. Development of in vitro systems for nanotoxicology: methodological considerations. Crit Rev Toxicol. 2009;39:613-26.

14. Klein SG, Serchi T, Hoffmann L, Blömeke B, Gutleb AC. An improved 3D tetraculture system mimicking the cellular organisation at the alveolar barrier to study the potential toxic effects of particles on the lung. Part Fibre Toxicol. 2013;10:31

15. Antunes F, Andrade F, Araújo F, Ferreira D, Sarmento B. Establishment of a triple co-culture in vitro cell models to study intestinal absorption of peptide drugs. Eur J Pharm Biopharm. 2013;83:427-35.
16. Bailey CA, Bryla P, Malick AW. The use of the intestinal epithelial cell culture model, Caco-2, in pharmaceutical development. Adv Drug Deliv Rev. 1996;22:85-103.

17. Walter E, Janich S, Roessler BJ, Hilfinger JM, Amidon GL. HT29-MTX/Caco-2 cocultures as an in vitro model for the intestinal epithelium: in vitro-in vivo correlation with permeability data from rats and humans. J Pharm Sci. 1996;85:1070-6.

18. Pathophysiology of the digestive system [http://www.vivo.colostate.edu/ hbooks/pathphys/digestion/index.html]

19. Pontier C, Pachot J, Botham R, Lenfant B, Arnaud P. HT29-MTX and Caco-2/ TC7 monolayers as predictive models for human intestinal absorption: role of the mucus layer. J Pharm Sci. 2001;90:1608-19.

20. Sigurdsson HH, Kirch J, Lehr CM. Mucus as a barrier to lipophilic drugs. Int J Pharm. 2013;453:56-64.

21. Cone RA. Barrier properties of mucus. Adv Drug Deliv Rev. 2009;61:75-85.

22. Larhed A, Artursson P, Björk E. The influence of instestinal mucus components on the diffusion of drugs. Pharm Res. 1998;15:66-71.

23. Jin F, Welch R, Glahn R. Moving toward a more physiological model: application of mucin to refine the in vitro digestion/Caco-2 cell culture system. J Agric Food Chem. 2006;54:8962-7.

24. Grès $M-C$, Julian B, Bourrié $M$, Meunier $V$, Roques $C$, Berger $M$, et al. Correlation between oral drug absorption in humans, and apparent drug permeability in TC-7 cells, a human epithelial intestinal cell line: comparison with the parental Caco-2 cell line. Pharm Res. 1998;15:726-33.

25. Lesuffleur T, Barbat A, Dussaulx E, Zweibaum A. Growth adaptation to methotrexate of HT-29 human colon carcinoma cells is associated with their ability to differentiate into columnar absorptive and mucus-secreting cells. Cancer Res. 1990;50:6334-43.

26. Mahler GJ, Shuler ML, Glahn RP. Characterization of Caco-2 and HT29-MTX cocultures in an in vitro digestion/cell culture model used to predict iron bioavailability. J Nutr Biochem. 2009;20:494-502.

27. Hilgendorf C, Spahn-Langguth H, Regårdh CG, Lipka E, Amidon GL, Langguth P. Caco-2 versus Caco-2/HT29-MTX co-cultured cell lines: permeabilities via diffusion, inside- and outside-directed carrier-mediated transport. J Pharm Sci. 2000;89:63-75.

28. Yuan H, Chen C, Chai G, Du Y, Hu F. Improved transport and absorption through gastrointestinal tract by PEGylated solid lipid nanoparticles. Mol Pharm. 2013;10:1865-73.

29. Leonard F, Collnot E-M, Lehr C. A three-dimensional coculture of enterocytes, monocytes and dendritic cells to model inflamed intestinal mucosa in vitro. Mol Pharm. 2010;7:2103-19.

30. Gehrke H, Frühmesser A, Pelka J, Esselen M, Hecht LL, Blank H, et al. In vitro toxicity of amorphous silica nanoparticles in human colon carcinoma cells. Nanotoxicology. 2013;7:274-93.

31. Tenzer S, Docter D, Kuharev J, Musyanovych A, Fetz V, Hecht R, et al. Rapid formation of plasma protein corona critically affects nanoparticle pathophysiology. Nat Nanotechnol. 2013;8:772-81.

32. Walczak AP, Fokkink R, Peters R, Tromp P, Herrera Rivera ZE, Rietjens IMCM, et al. Behaviour of silver nanoparticles and silver ions in an in vitro human gastrointestinal digestion model. Nanotoxicology. 2012;7:1198-210.

33. Gliga AR, Skoglund S, Wallinder IO, Fadeel B, Karlsson HL. Size-dependent cytotoxicity of silver nanoparticles in human lung cells: the role of cellular uptake, agglomeration and Ag release. Part Fibre Toxicol. 2014;11:11.

34. Brownlee IA, Knight J, Dettmar PW, Pearson JP. Action of reactive oxygen species on colonic mucus secretions. Free Radic Biol Med. 2007:43:800-8.

35. Stepkowski TM, Brzóska K, Kruszewski M. Silver nanoparticles induced changes in the expression of NF-kB related genes are cell type specific and related to the basal activity of NF-kB. Toxicol In Vitro. 2014;28:473-8.

36. Moll R, Divo M, Langbein L. The human keratins: biology and pathology. Histochem Cell Biol. 2008;129:705-33.

37. Weng Y, Cui Y, Fang J. Biological functions of cytokeratin 18 in cancer. Mol Cancer Res. 2012;10:485-93.

38. Wang L, Srinivasan S, Theiss AL, Merlin D, Sitaraman S V. Interleukin-6 induces keratin expression in intestinal epithelial cells. Potential role of keratin-8 in interleukin-6-induced barrier function alterations. J Biol Chem. 2007;282:8219-27.

39. Baranwal S, Naydenov NG, Harris G, Dugina V, Morgan KG, Chaponnier C, et al. Nonredundant roles of cytoplasmic $\beta$ - and $\gamma$-actin isoforms in regulation of epithelial apical junctions. Mol Biol Cell. 2012;23:3542-53.

40. Ku N-O, Zhou X, Toivola D, Omary BM. The cytoskeleton of digestive epithelia in health and disease. Am J Physiol Gastrointest Liver Physiol. 1999;277:G1108-1137. 
41. Levy E, Ménard D, Delvin E, Montoudis A, Beaulieu J-F, Mailhot G, et al. Localization, function and regulation of the two intestinal fatty acid-binding protein types. Histochem Cell Biol. 2009;132:351-67.

42. Pelsers MMAL, Namiot Z, Kisielewski W, Namiot A, Januszkiewicz M, Hermens WT, et al. Intestinal-type and liver-type fatty acid-binding protein in the intestine. Tissue distribution and clinical utility. Clin Biochem. 2003;36:529-35

43. Ulmasov B, Bruno J, Woost PG, Edwards JC. Tissue and subcellular distribution of CLIC1. BMC Cell Biol. 2007;8:8.

44. Singh $\mathrm{H}$, Cousin MA, Ashley $\mathrm{RH}$. Functional reconstitution of mammalian "chloride intracellular channels" CLIC1, CLIC4 and CLIC5 reveals differential regulation by cytoskeletal actin. FEBS J. 2007;274:6306-16.

45. Ma P-F, Chen J-Q, Wang Z, Liu J-L, Li B-P. Function of chloride intracellular channel 1 in gastric cancer cells. World J Gastroenterol. 2012;18:3070-80.

46. Averaimo S, Milton RH, Duchen MR, Mazzanti M. Chloride intracellular channel 1 (CLIC1): sensor and effector during oxidative stress. FEBS Lett. 2010;584:2076-84.

47. Varki A. Sialic acids in human health and disease. Trends Mol Med. 2008;14:351-60.

48. Schauer R. Sialic acids and their role as biological masks. Trends Biochem Sci. 1985;10:357-60.

49. Yusuf S, Nok AJ, Ameh DA, Adelaiye AB, Balogun EO. Correlation of gastric mucosal damage with sialic acid profile in rats: effect of hydrochloric acid, pepsin and hypertonic saline. Cell Biochem Funct. 2005;23:339-45.

50. Gudas L, Ullman B, Cohen A, Martin Jr D. Deoxyguanosine toxicity in a mouse T Iymphoma: relationship to purine nucleoside phosphorylase-associated immune dysfunction. Cell. 1978;14:531-8.

51. Papinazath T, Min W, Sujiththa S, Cohen A, Ackerley C, Roifman C, et al. Effects of purine nucleoside phosphorylase deficiency on thymocyte development. J Allergy Clin Immunol. 2011;128:854-63. e1.

52. Nigro P, Pompilio G, Capogrossi MC. Cyclophilin A: a key player for human disease. Cell Death Dis. 2013;4:e888.

53. Sun S, Wang Q, Giang A, Cheng C, Soo C, Wang C-Y, et al. Knockdown of CypA inhibits interleukin-8 (IL-8) and IL-8-mediated proliferation and tumor growth of glioblastoma cells through down-regulated NF-kB. J Neurooncol. 2011;101:1-14

54. Chen S, Zhang M, Ma H, Saiyin H, Shen S, Xi J, et al. Oligo-microarray analysis reveals the role of cyclophilin $\mathrm{A}$ in drug resistance. Cancer Chemother Pharmacol. 2008;61:459-69.

55. Herzog A, Kuntz S, Daniel H, Wenzel U. Identification of biomarkers for the initiation of apoptosis in human preneoplastic colonocytes by proteome analysis. Int J Cancer. 2004;109:220-9.

56. Massey D, Traverso V, Rigal A, Maroux S. Cellular and subcellular localization of annexin IV in rabbit intestinal epithelium, pancreas and liver. Biol Cell. 1991;73:151-6

57. Weiske J, Huber O. The histidine triad protein Hint1 triggers apoptosis independent of its enzymatic activity. J Biol Chem. 2006;281:27356-66.

58. Wang Y, Srinivasan K, Siddiqui MR, George SP, Tomar A, Khurana S. A novel role for villin in intestinal epithelial cell survival and homeostasis. J Biol Chem. 2008;283:9454-64.

59. Vannini C, Domingo G, Onelli E, Prinsi B, Marsoni M, Espen L, et al. Morphological and proteomic responses of Eruca sativa exposed to silver nanoparticles or silver nitrate. PLoS One. 2013;8:e68752.

60. Imai T, Imoto M, Sakamoto $H$, Hashimoto M. Identification of esterases expressed in Caco-2 cells and effects of their hydrolyzing activity in predicting human intestinal absorption. Drug Metab Dispos. 2005;33:1185-90.

61. Hayes JD, Flanagan JU, Jowsey IR. Glutathione transferases. Annu Rev Pharmacol Toxicol. 2005;45:51-88.

62. Manevich $Y$, Fisher AB. Peroxiredoxin 6, a 1-Cys peroxiredoxin, functions in antioxidant defense and lung phospholipid metabolism. Free Radic Biol Med. 2005;38:1422-32.

63. Wang Z, Cheng Y, Wang N, Wang D, Li Y, Han F, et al. Dioscin induces cancer cell apoptosis through elevated oxidative stress mediated by downregulation of peroxiredoxins. Cancer Biol Ther. 2012;13:138-47.

64. Zhang H, Forman $\mathrm{HJ}$. Glutathione synthesis and its role in redox signaling. Semin Cell Dev Biol. 2012;23:722-8.

65. Spielberg S, Gordon G. Glutathione synthetase-deficient lymphocytes and acetaminophen toxicity. Clin Pharmacol Ther. 1981;29:51-5.

66. Drozdowski L, Thomson ABR. Intestinal mucosal adaptation. World J Gastroenterol. 2006;12:4614-27.
67. Anselmo HMR, van den Berg JHJ, Rietjens IMCM, Murk AJ. Inhibition of cellular efflux pumps involved in multi xenobiotic resistance (MXR) in echinoid larvae as a possible mode of action for increased ecotoxicological risk of mixtures. Ecotoxicology. 2012;21:2276-87.

68. Bhattacharjee S, Ershov D, Gucht JVD, Alink GM, Rietjens IMCM, Zuilhof H, et al. Surface charge-specific cytotoxicity and cellular uptake of tri-block copolymer nanoparticles. Nanotoxicology. 2013;7:71-84.

69. Georgantzopoulou A, Balachandran YL, Rosenkranz P, Dusinska M, Lankoff A Wojewodzka M, et al. Ag nanoparticles: size- and surface-dependent effects on model aquatic organisms and uptake evaluation with NanoSIMS. Nanotoxicology. 2013;7:1168-78.

70. Lankoff A, Sandberg WJ, Wegierek-ciuk A, Lisowska H, Refsnes M, Schwarze PE, et al. The effect of agglomeration state of silver and titanium dioxide nanoparticles on cellular response of HepG2, A549 and THP-1 cells. Toxicol Lett. 2012;208:197-213.

71. Kruszewski M, Grądzka I, Bartłomiejczyk T, Chwastowska J, Sommer S, Grzelak A, et al. Oxidative DNA damage corresponds to the long term survival of human cells treated with silver nanoparticles. Toxicol Lett. 2013;219:151-9.

72. Boscher A, Gobert S, Guignard C, Ziebel J, L'Hoste L, Gutleb AC, et al. Chemical contaminants in fish species from rivers in the North of Luxembourg: potential impact on the Eurasian otter (Lutra lutra). Chemosphere. 2010;78:785-92

73. Audinot J-N, Senou M, Migeon H-N, Many M-C. Visualisation of thyroid hormone synthesis by ion imaging. Appl Surf Sci. 2008;255:1185-9.

74. Gutleb AC, Freitas J, Murk AJ, Verhaegen S, Ropstad E, Udelhoven T, et al. NanoSIMS50- a powerful tool to elucidate cellular localization of halogenated organic compounds. Anal Bioanal Chem. 2012;404:2693-8.

75. Lasserre J-P, Fack F, Serchi T, Revets D, Planchon S, Renaut J, et al. Atrazine and PCB 153 and their effects on the proteome of subcellular fractions of human MCF-7 cells. Biochim Biophys Acta. 2012;1824:833-41.

76. Pasquali M, Serchi T, Renaut J, Hoffmann L, Bohn T. 2D difference gel electrophoresis reference map of a Fusarium graminearum nivalenol producing strain. Electrophoresis. 2013;34:505-9.

\section{Submit your next manuscript to BioMed Central and we will help you at every step:}

- We accept pre-submission inquiries

- Our selector tool helps you to find the most relevant journal

- We provide round the clock customer support

- Convenient online submission

- Thorough peer review

- Inclusion in PubMed and all major indexing services

- Maximum visibility for your research

Submit your manuscript at www.biomedcentral.com/submit
(O) BioMed Central 